\title{
Discontinuous Precipitation in Ni-Base Superalloys During Solution Heat Treatment
}

\author{
D. WELTON, N. D'SOUZA, J. KELLEHER, S. GARDNER, Z.H. DONG, G.D. WEST, \\ and HONGBIAO DONG
}

\begin{abstract}
Discontinuous precipitation in single-crystal Ni-base superalloys during solution heat treatment has been studied. It is found that discontinuous precipitation occurs at temperatures approaching the solvus, where volume diffusion is dominant. Diffusion of $\mathrm{Al}$ ahead of the boundary leads to gamma prime precipitation and is accompanied by a loss in the driving force available for advancement of the grain boundary. The rate of gamma prime precipitation was tracked using in situ neutron diffraction during isothermal hold. Gamma prime precipitation is accompanied by super-saturation of $\mathrm{Cr}$ and $\mathrm{W}$ within the channels ahead of the interface. The driving force calculated for the initial stages of DP was [10-5 to $10-4] \mathrm{N} /\left[\mu \mathrm{m}^{2}\right.$ of the grain boundary]. The results provide an insight into discontinuous precipitation during solution heat treatment of Ni-base single-crystal alloys and are useful in optimizing the heat treatment process to avoid surface defect formation.
\end{abstract}

DOI: $10.1007 / \mathrm{s} 11661-015-3046-6$

(C) The Author(s) 2015. This article is published with open access at Springerlink.com

\section{INTRODUCTION}

SUPERALLOYS are class of materials that have been specifically designed for high-temperature applications. Of these, the newer generation Ni-base alloys, such as CMSX-10N have been developed for elevated creep strength and therefore contain increasing amounts of the refractory elements such as Ta, W, and Re. ${ }^{[1]}$ Turbine blades made from Ni-base alloys are investment cast and often in single-crystal form. For cooling rates used in industrial practise the as-cast microstructure comprises $\gamma$ dendrites and non-equilibrium inter-dendritic phase. This is attributed to severe solidification segregation from elemental partitioning at the solid/ liquid interface and the relatively slow diffusivities of refractory elements in the solid. As a result heat treatment is required to homogenize the microstructure and dissolve the inter-dendritic eutectic phase. Heat treatment processing comprises two stages: (1) Solutioning $\sim\left[1573 \mathrm{~K}\right.$ to $1633 \mathrm{~K}\left(1300{ }^{\circ} \mathrm{C}\right.$ to $\left.\left.1360{ }^{\circ} \mathrm{C}\right)\right]$ and Primary aging $\sim\left[1273 \mathrm{~K}\right.$ to $1423 \mathrm{~K} \quad\left(1000{ }^{\circ} \mathrm{C}\right.$ to $\left.\left.1150^{\circ} \mathrm{C}\right)\right]$. Solutioning (1) is carried out above the

D. WELTON, Turbines Laboratory Cast Team Lead, and N. D'SOUZA, Materials Technologist, are with the Rolls-Royce plc, PO Box 31, Derby, DE24 8BJ, U.K. J. KELLEHER, ENGIN-X Beamline Scientist, is with the ISIS Facility, Science, Technology and Facilities Council, Rutherford Appleton Laboratory, Harwell Oxford, Didcot, Oxfordshire OX11 0QX, U.K. S. GARDNER, Ph.D. Student, is with the Department of Engineering, Swansea University, Singleton Park, Swansea SA2 8PP, U.K. Z.H. DONG, Ph.D. Student, and HONGBIAO DONG, Professor, are with the Department of Engineering, University of Leicester, Leicester, LE1 7RH, U.K. Contact e-mail: h.dong@le.ac.uk G.D. WEST, Research Fellow, is with the Materials Department, Loughborough University, Loughborough, Leicestershire, LE11 3TU, U.K.

Manuscript submitted January 13, 2015.

Article published online July 14, 2015 $\gamma^{\prime}$-solvus temperature where long-range diffusion is dominant leading to homogenization and dissolution of inter-dendritic eutectic phase. Primary aging (2) is subsequently required to re-precipitate and grow the optimum cuboidal $\gamma^{\prime}$ phase. After heat treatment, the turbine blades are often coated to improve high-temperature environmental stability and oxidation resistance. The latter is achieved by preferentially growing an $\mathrm{Al}_{2} \mathrm{O}_{3}$ layer, which has good adherence to the substrate. This is done by locally increasing the $\mathrm{Al}$ content at the surface using an aluminization process. ${ }^{[1]}$

Discontinuous precipitation (DP) refers to an abrupt change in composition and orientation between parent phase and product phases. ${ }^{[2]}$ It has been observed in the substrate beneath coating $s^{[3-5]}$ or on grain boundaries. ${ }^{[6-8]}$ In all cases, there is the requirement of a super-saturated matrix, which provides the driving force for growth. ${ }^{[2]} \mathrm{In}$ multi-component Ni-base superalloys, DP morphology constitutes a polycrystalline colony comprising of $\gamma^{\prime}$ matrix with/without $\gamma$-lamellae and needle-like tetragonal close-packed (TCP) phases segregated in $\mathrm{Cr}, \mathrm{W}$, and $\mathrm{Re}$, which constitute the precipitate. ${ }^{[3-8]}$ The advancement of the DP zone occurs by partitioning of $\mathrm{Cr}, \mathrm{W}$, and $\mathrm{Re}$ to the growing tips of the precipitates along the grain boundary.

In Ni-base alloys, it has been mentioned above that DP zones occur in two distinct regions:

(i) Randomly within the microstructure by nucleating on pre-existing grain boundaries - the reaction can be written as $\gamma_{\mathrm{SS}} \rightarrow \gamma+\mathrm{TCP}$, where "ss" refers to super-saturated in $\mathrm{Cr}, \mathrm{W}$, and $\mathrm{Re}^{\left[{ }^{[6-8]}\right.}$

(ii) Beneath an aluminized or Pt-aluminized surface coating - the reaction can be written as $\gamma+\mathrm{Al} \rightarrow$ $\gamma^{\prime}+$ TCP and in this case the DP zone is also referred to as the "secondary reaction zone" or SRZ. ${ }^{[3-5]}$ 
It should be pointed out that DP is also referred to as "Type II" re-crystallization. This occurs when re-crystallization originates at the surface and more importantly occurs below the solvus temperature. ${ }^{[9-13]}$ During advancement of the grain boundary into the $\gamma / \gamma^{\prime}$ substrate, dissolution of $\gamma^{\prime}$ precipitates occur at the moving boundary followed by discontinuous re-precipitation of $\gamma^{\prime}$ once the boundary has advanced. ${ }^{[14]}$

DP in turbine blades has significant implications on performance. Depletion of $\mathrm{W}$ and $\mathrm{Re}$ from the bulk matrix leading to precipitation and growth of TCP phases results in a loss of solid-solution hardening associated with these alloying elements and therefore a concomitant decrease in creep strength.

The driving force for DP in binary systems has been treated in detail by Hillert. ${ }^{[15,16]}$ Through a simple thermo-dynamical argument it was shown that a driving force for migration of the grain boundary can only exist if there is loss of interfacial equilibrium at the interface. Consequently, some fraction of the driving force not lost to volume diffusion becomes available as a "force" to pull the grain boundary. Various sinks for the driving force include volume diffusion of the solute ahead of the interface, intrinsic and solute drag energies, and capillarity from the curvature of the precipitate tips. ${ }^{[17]}$ While this approach is elegant in its simplicity for a binary alloy system, all commercial alloys of engineering significance are multi-component and an assessment of the driving force for DP requires defining a method for calculating the driving force in such cases.

In this article, we present a detailed examination of discontinuous precipitation in multi-component systems at the casting surface during solution heat treatment, with specific reference to a Ni-base alloy, CMSX-10N, Table I. In particular, we show that

1. DP has two distinct stages, i.e., initial and later stages of growth and we calculate the chemical driving force for both these cases from thermodynamics using reasonable approximations. In particular, we will aim to show that in the later stages there is a loss in chemical driving force.

2. We present experimental evidence for the loss of driving force through volume diffusion.

a. Using in-situ solutioning it is possible to progressively track solute diffusion ahead of the interface and by using neutron diffraction it is possible to identify the resulting phase transformations.

b. Through a novel experiment we also demonstrate the response of a grain boundary to remnant strain when all chemical driving force has been consumed, i.e. the occurrence of grain boundary pinning.

\section{EXPERIMENTAL METHODS}

A systematic study was carried out to study the discontinuous precipitation (DP) morphology at the surface and also the phase evolution ahead of the interface during solutioning using in situ neutron diffraction. Detailed micro-structural analysis has been carried out using scanning and transmission electron microscopy to identify the different phases that form and the accompanying elemental segregation. Further, thermal analysis was carried out to determine the key phase transformation temperatures.

\section{A. Sample Preparation for In Situ Solutioning and Neutron Diffraction}

All the test bar samples were single crystal. Directional solidification was carried out at the Precision Casting Facility, Rolls-Royce, plc, Derby, UK. Cylindrical test bars (70 $\mathrm{mm}$ in length with a $10 \mathrm{~mm}$ diameter) were cast in an industrial directional solidification furnace. The basic parameters included the following: furnace heater temperature was nominally $1773 \mathrm{~K}\left(1500{ }^{\circ} \mathrm{C}\right)$, vacuum level of the furnace chamber was maintained at $0.1 \mathrm{~Pa}$ $\left(10^{-6} \mathrm{~atm}\right)$, and a mold withdrawal rate of around $5 \times 10^{-5} \mathrm{~m} \mathrm{~s}^{-1}$. The bars were chosen such that the bar axis was within 5 deg from the [001] crystal axis.

1. Heat treatment to produce fully solutioned test bar

A Schmetz furnace with a cuboidal working volume was used for heat treatment. Solution heat treatment cycle took place under Ar pressure of $50 \mathrm{~Pa}(5 \times$ $\left.10^{-4} \mathrm{~atm}\right)$. The solution heat treatment cycle consisted of numerous isothermal holds along the ramp cycle up to the final soak temperature of $1636 \mathrm{~K}\left(1363^{\circ} \mathrm{C}\right)$. The test bars were positioned on ceramic tiles within the center of the furnace working volume and held at $1636 \mathrm{~K}$ $\left(1363{ }^{\circ} \mathrm{C}\right)$ for 25 hours. Following completion of the top soak phase, the bars were rapidly gas fan quenched using forced Ar flow giving an approximate cooling rate of $240 \mathrm{~K} \mathrm{~min}^{-1}$. The test bars underwent primary aging in the same furnace at $1423 \mathrm{~K}\left(1150^{\circ} \mathrm{C}\right)$ for 5 hours under a vacuum level of $0.1 \mathrm{~Pa}\left(10^{-6} \mathrm{~atm}\right)$ and subsequently rapidly gas fan quenched using Ar.

\section{Post-heat treat sample preparation}

The test bars for the in situ experiments corresponded to those that were fully solutioned and primary aged. The [100] and [010] axes were marked on the circular cross sections and the bars were subsequently cut along these lines using wire Electrical Discharge Machining (EDM) at Matlock Wire, Derby, UK. Four bars were thereby obtained from a cylindrical test bar (diameter $12 \mathrm{~mm}$ ), such that the cross sections had a quadrant shape and the

Table I. Nominal Composition (Weight Percent) of Alloying Elements in CMSX10N

\begin{tabular}{llllllllll}
\hline Alloy & $\mathrm{Al}$ & $\mathrm{Co}$ & $\mathrm{Cr}$ & $\mathrm{Ti}$ & Mo & Ta & W & Re & Ni \\
\hline CMSX10N & 5.9 & 3.1 & 1.6 & 0.1 & 0.45 & 8.5 & 5.5 & 6.8 & bal \\
\hline
\end{tabular}


two straight edges joining the curved surface were close to [100] and [010]. The bars were $6 \mathrm{~cm}$ in length. Upon sectioning, the bars were subsequently grit-blasted using an $\mathrm{Al}_{2} \mathrm{O}_{3}$ media to remove any surface re-cast layer that might have formed during the wire EDM process.

\section{B. Measurement of Gamma Prime $\left(\gamma^{\prime}\right)$ Evolution During Solutioning using In Situ Neutron Diffraction}

An in situ heat treatment (repeat heat treatment) was carried out inside the ENGIN-X hutch using GEM furnace with $\mathrm{Nb}$ heating elements at ISIS, Rutherford Appleton Laboratory, UK. The pressure in the furnace pressure was maintained $10^{-8}$ atm using an $\mathrm{AC}$ motor pump. An initial ramp rate of by $10 \mathrm{~K} \mathrm{~min}^{-1}$ was followed by an intermediate isothermal hold at $1523 \mathrm{~K}\left(1250{ }^{\circ} \mathrm{C}\right)$ for 90 minutes to allow the furnace temperature to equilibrate. This was then followed by ramping at $5 \mathrm{~K} \mathrm{~min}^{-1}$ until the final temperature was attained. A final top soak temperature of $1623 \mathrm{~K}\left(1350{ }^{\circ} \mathrm{C}\right)$ was used and this was followed by an isothermal hold for 14 hours. The sample was mounted vertically on a ceramic base with additional ceramic supports to prevent movement, as observed in Figure 1(a). Specimens were secured to the furnace plunger using Ta wire with ceramic piping preventing contact between the wire, plunger, and specimen. The sample was then secured using Ta wire. A dummy specimen was mounted opposite the target sample to act as a counter balance. Type $\mathrm{W}$ thermocouples were positioned on the curved face of the sample to measure the temperature during the heat treatment process and to provide furnace temperature control. The outer flat target surface was aligned parallel to the incoming beam first visually then more accurately using the imaging detector. A schematic of the sample set-up is shown in Figure 1(b). The holder was installed inside the furnace and the sample firmly attached on the holder to prevent any disturbance.
To ensure the neutron beam targets the correct position on the sample, the flat surface of quadrant cross section was made parallel to the emitting direction of the neutron beam. Therefore, the long edge of sample was adjusted to be in position vertically parallel to the sample holder. Detectors at 90 deg to the sample were used to measure the $\gamma$ and $\gamma^{\prime}$ peaks.

\section{Interrupted Solutioning Experiments}

Solutioning experiments using directionally solidified test bars were also conducted in a TAV vacuum furnace at the University of Birmingham, UK. All solutioning experiments were conducted in an Ar atmosphere at a pressure of $2 \times 10^{-4}$ atm $(0.2 \mathrm{mBar})$. The test bars were both in the grit-blasted and non-grit-blasted condition (pristine as-cast surface). The test bars were located in alumina boats and positioned in the center of the furnace, which was fitted with eight thermocouples at the corners and one at the center of the load. Heating involved a series of ramps and isothermal holds until the set temperature was attained and a soak of 0.5 hour at top temperature was used. In this case, a set temperature of $1563 \mathrm{~K}\left(1290{ }^{\circ} \mathrm{C}\right)$ was used. After completion of the top soak phase quenching was done in an argon flow at approximately $90 \mathrm{~K} \mathrm{~min}^{-1}$. In one instance, a sample was heated up to $1633 \mathrm{~K}\left(1360{ }^{\circ} \mathrm{C}\right)$ and then isothermally held for 1 hour before quenching.

\section{Electron Microscopy}

The bars were cross sectioned, Au sputtered, and Ni electro-plated to preserve the surface during subsequent sample preparation. The cross sections were taken and mounted in conductive bakelite. The samples were polished starting with $\mathrm{SiC}$ grit paper, progressing through to 9 and $3 \mu \mathrm{m}$ diamond paste. Finally, the
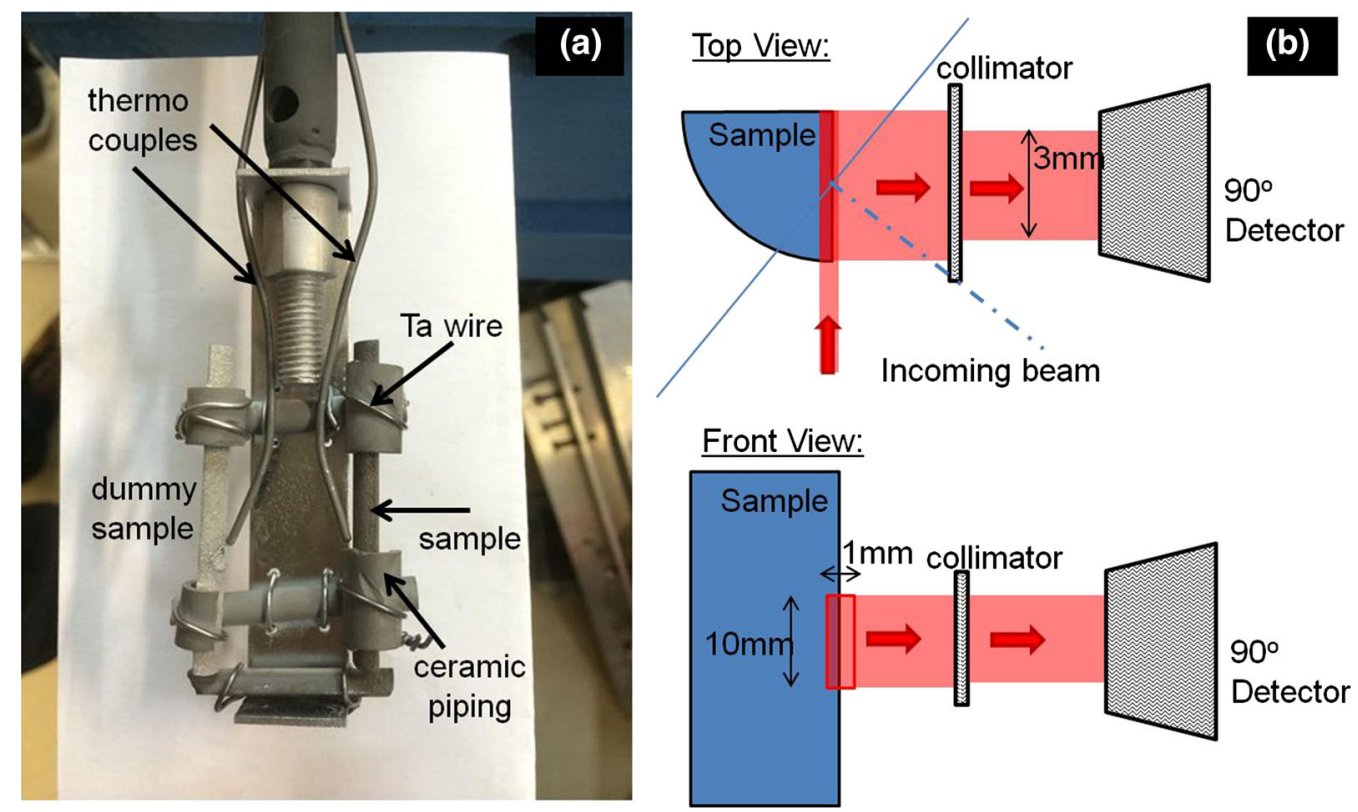

Fig. 1-Experimental set-up for solutioning heat treatment with in situ neutron diffraction: $(a)$ sample configuration; (b) schematic diagram showing sample disposition with respect to incoming neutron beam and positioning of detectors. 
samples were mechano-chemically polished on a Vibromet using colloidal silica for 8 hours.

\section{Scanning electron microscopy (SEM)}

All scanning electron microscopy (SEM) was performed using a dual beam (FEI Nova 600 Nanolab), focused ion beam (FIB)/field emission gun scanning electron microscope (FEG-SEM). Back-scattered electron images (BEI) were collected using a retractable solid-state back-scatter detector using high $(20 \mathrm{kV})$ electron beam accelerating voltages for enhanced compositional contrast. Chemical analysis was undertaken in this system at $20 \mathrm{kV}$ using energy dispersive spectroscopy (EDS) using an Octane super $60 \mathrm{~mm}^{2}$ silicon drift detector (SDD) from EDAX. Kikuchi patterns for electron back-scattered diffraction (EBSD) were collected using a Hikari XP camera (EDAX). Patterns were collected and indexed according to the Ni structure file at a rate of 300 frames s$^{-1}$. A beam voltage of $20 \mathrm{kV}$ with a nominal current of $6.6 \mathrm{nA}$ was used. Orientation data were collected and analyzed using OIM software (version 6.2) from EDAX. Images were displayed without cleaning as image quality (IQ) and image quality overlaid with grain orientation (inverse pole figure) maps.

\section{Scanning transmission electron microscopy} (STEM)

The dual beam system was also used to prepare site specific TEM samples using an in situ lift-out procedure. This involves depositing $\mathrm{Pt}$ using the gas injection system (GIS) over the $20 \mu \mathrm{m}$ long area of interest, and milling "stair-case" trenches on either side. The TEM sample was extracted using an omniprobe micromanipulator and was attached to a $\mathrm{Cu}$ grid. Great care was taken when final thinning to achieve samples that all had similar and uniform thickness.

STEM analysis was performed in a FEI Tecnai F20 operating at $200 \mathrm{kV}$. The system is equipped with an Oxford instruments XMAXN 80 TLE windowless SDD EDS detector. Images were collected with a bright field (BF) and High Angular Annular Dark Field (HAADF) detectors in STEM. EDS spectrum maps were collected using Aztec software to assess sample compositional homogeneity. From these maps, regions for collecting comparative spectra were defined and these were collected for $20 \mathrm{~s}$ live time.

\section{E. Differential Thermal Analyses (DTA)}

A Stanton Redcroft 1640 Differential Thermal Analyses unit (DTA) was used for the experiments incorporating cylindrical samples (diameter $4 \mathrm{~mm}$, height $3 \mathrm{~mm}$ ). All experiments were conducted using a dynamic high-purity Ar atmosphere to minimize potential oxidizing effects. The unit was calibrated using pure metals with melting points of $1337 \mathrm{~K}\left(1064{ }^{\circ} \mathrm{C}\right) \mathrm{Au}$ and $1726 \mathrm{~K}\left(1453^{\circ} \mathrm{C}\right) \mathrm{Ni}$. Alumina crucibles were used in all DTA experiments. The thermal resistances between different regions of the instrument were calibrated by fitting experimental data of melting pure nickel. With

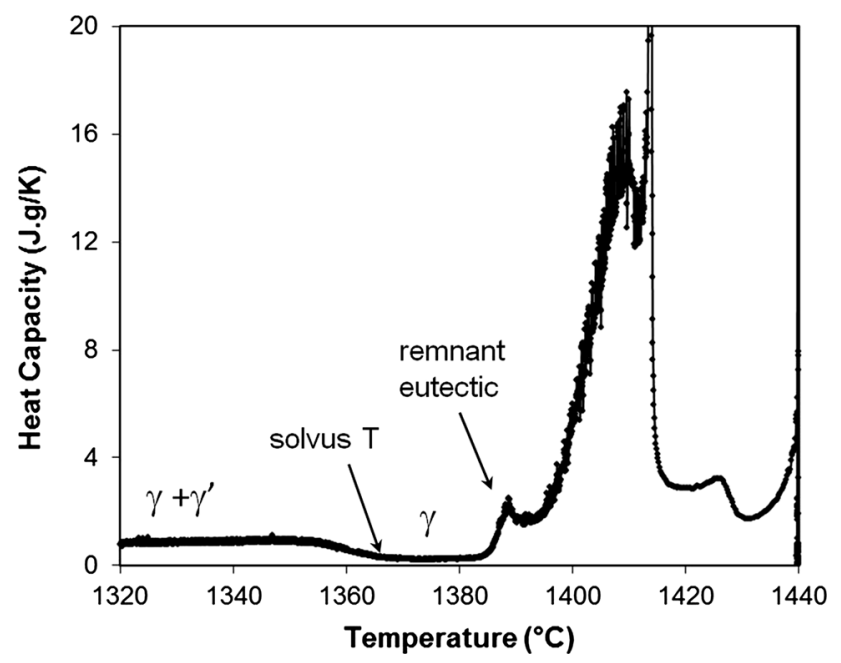

Fig. 2-DTA heating curve of a near-solutioned sample showing limited remnant non-equilibrium eutectic and $\gamma^{\prime}$-solvus temperature (heating rate of $2 \mathrm{~K} \mathrm{~min}^{-1}$ ).

the calibrated thermal resistances for the instrument, the program is able to de-convolute the measured signals and to extract accurate transition temperatures and enthalpy changes from the DTA measurements. ${ }^{[18]}$ Figure 2 corresponds to the heating curve of a solutioned bar (Section II-A), where a heating rate of $2 \mathrm{~K} \mathrm{~min}^{-1}$ was used. Very limited un-dissolved eutectic $(\sim 2.5 \mathrm{pct})$ exists and accounting for the minor endothermic peak. Importantly, however, the $\gamma^{\prime}$-solvus temperature is $1638 \mathrm{~K}\left(1365^{\circ} \mathrm{C}\right)$ and single-phase $\gamma$ exists in the temperature range $1638 \mathrm{~K} \leq T \leq 1655 \mathrm{~K}\left[1365{ }^{\circ} \mathrm{C} \leq\right.$ $T \leq 1382{ }^{\circ} \mathrm{C}$ ).

\section{RESULTS}

\section{A. Development of Discontinuous Precipitation Cells at the Surface During Solution Heat Treatment}

Discontinuous precipitation (DP) is observed even during the ramping stage well below the solvus temperature. The BEI in Figure 3(a) corresponds to a cross section from a test bar from an interrupted solutioning experiment $\left[T=1563 \mathrm{~K}\left(1290{ }^{\circ} \mathrm{C}\right)\right]$, while Figure 3(b) is an orientation-image map (OIM) derived inverse pole figure (IPF). Three distinct zones can be delineated beneath the surface after ignoring the sputtered $\mathrm{Au}$ layer and electro-deposited $\mathrm{Ni}$ layer to preserve the surface topography during subsequent metallographic grinding and polishing. The evolution of the microstructure was found to be independent of the nature of the as-cast surface, i.e., grit- or non-grit-blasted, which indicates that the role of the induced surface strain per se can be considered as secondary. The following observations can be made:

Below the sample surface [interrupted $1563 \mathrm{~K}$ $\left(1290{ }^{\circ} \mathrm{C}\right)$ heat treatment],

(i) Nucleation of $\beta$-islands occurs beneath the surface and constitutes the outer layer with a thickness $\sim 5 \mu \mathrm{m}$. The composition determined 

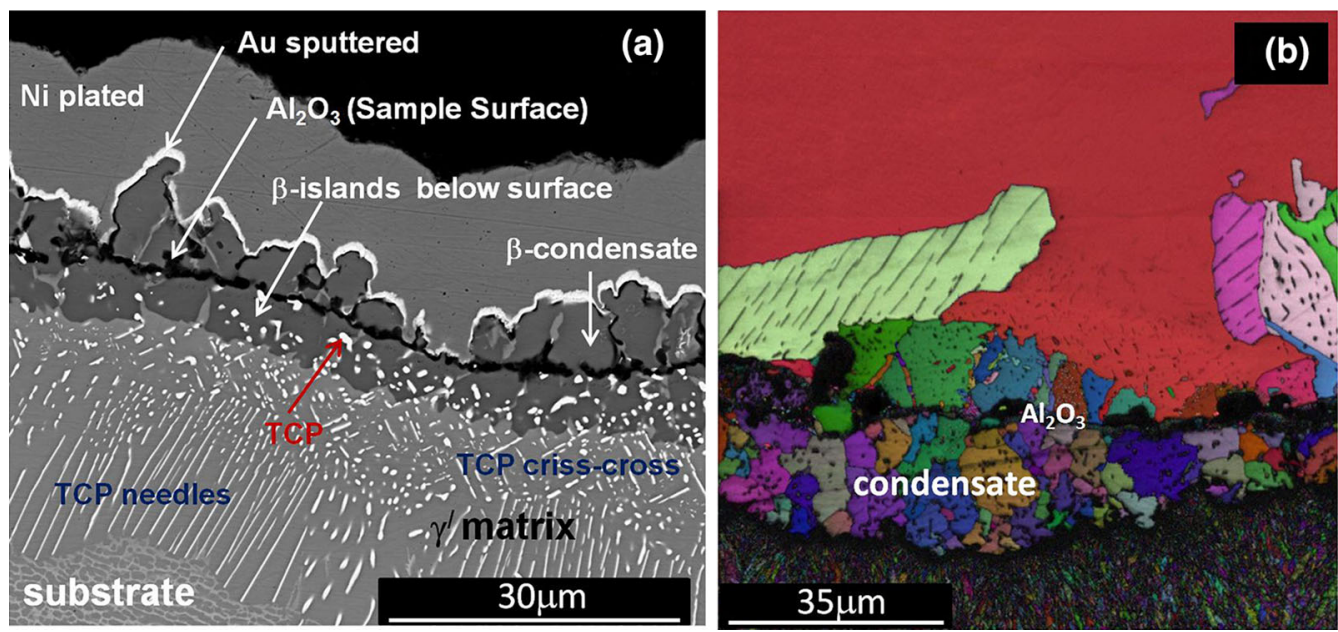

Fig. 3-Phases at initial stages of discontinuous precipitation: (a) Back-scattered electron image (BEI), (b) Inverse pole figure (IPF) derived orientation-image map (OIM).

by EDS gives $\left[\frac{\mathrm{Ni}}{\mathrm{Al}}\right]=\left[\frac{58}{36}\right]$ atomic ratio and indicates that the outer layer corresponds to $\beta$ phase. There is precipitation of refractory-rich (TCP) phases within this layer.

(ii) $\gamma^{\prime}$ layer with refractory-rich (TCP) phases having "criss-cross" morphology with thickness $\sim 5 \mu \mathrm{m}$. The composition measured by EDS yields $\left.\left[\frac{\mathrm{Ni}}{\mathrm{Al}}\right]=\left[\frac{74}{15}\right]\right]$ atomic ratio, indicating $\gamma^{\prime}$ phase. The remaining atomic percent is $\mathrm{Co}=2.5, \mathrm{Cr}=$ $0.75,[\mathrm{Ta}+\mathrm{W}+\mathrm{Re}]=6.75$.

(iii) Discontinuous precipitation morphology, comprising of refractory (W and Re)-rich (TCP) phases with a typical needle-like morphology [unlike in (ii)] within a $\gamma^{\prime}$ matrix. The DP zone comprises solely of $\left[\gamma^{\prime}+\right.$ TCP (needle-like morphology)] and the thickness of this zone is $\sim 20 \mu \mathrm{m}$.

(iv) The entire surface morphology is polycrystalline. The advancement of the DP zone is outlined by the growing tips of the TCP needles. The TCP phases produce poor EBSD patterns and consequently appear dark in the EBSD-derived image quality (IQ) maps.

The sample surface is demarcated by the occurrence of an intermittent $\mathrm{Al}_{2} \mathrm{O}_{3}$ layer. Above the surface, there is the presence of a $\beta$-condensate layer, which most likely forms during cooling and this fact is further corroborated by the polycrystalline random orientation of the grains, as observed in the OIM in Figure 3(b).

Growth of the DP zone was also investigated just below the solvus temperature $\left[1623 \mathrm{~K}\left(1350^{\circ} \mathrm{C}\right)\right]$ following an isothermal hold. The BEI in Figure 4(a) is a low-magnification BEI that presents an overview of the surface (quadrant), with specific emphasis to the flat faces, which were directly "exposed" to the furnace environment, i.e., no shielding; c.f. Figures 1(a) and (b). Figure 4(b) is a high-magnification image that focuses on key aspects of the microstructure. The microstructure at the starting condition of the samples (i.e., solutioned and primary aged-Section II-A).
The following can be observed:

Below the sample surface [after isothermal hold for 14 hours at $\left.1623 \mathrm{~K}\left(1350^{\circ} \mathrm{C}\right)\right]$ :

Significant changes to the microstructure occur during heat treatment close to the solvus temperature during isothermal hold.

(a) There is the occurrence of a "bright" phase that is nearly continuous across the surface, which is enriched in refractory elements.

(b) There is the distinct absence of the outermost $\beta$-islands, unlike in Figure 3(a). Rather, the $\beta$-islands are principally replaced by the growth of the DP zone up to the surface

(c) The $\beta$-islands are principally replaced by the DP zone that extends up to the surface. In sporadic regions, the DP zone has not grown up to the surface and there is the presence of another phase, which appears "grey". This is clearly not $\beta$, since it is brighter than the $\gamma^{\prime}$ matrix, which constitutes the DP zone that is located below.

(d) Growth of the DP zone also occurs into the substrate. Ingress of the zone at the end of the $1623 \mathrm{~K}\left(1350^{\circ} \mathrm{C}\right)$ isothermal hold is $\sim 120 \mu \mathrm{m}$. The substrate beneath the DP zone shows the distinct presence of coarse $\gamma^{\prime}$ precipitates (islands) interspersed between the usual $\gamma / \gamma^{\prime}$ morphology. This was markedly absent in the early stages of DP.

Figures 5(a) through (d) are elemental EDS maps that correspond to $\mathrm{Au}, \mathrm{Ni}, \mathrm{Al}$, and $\mathrm{Re}$, respectively. After careful delineation of the sputtered Au layer and the electro-plated Ni layer, it can be observed that the surface "bright" phase; c.f. point (a) is enriched in Re and W (W EDS map not included for brevity). Also, the "grey phase" that occurs sporadically, c.f. point (c) is clearly denuded in Al. However, since this layer is distinctly "bright" compared to $\gamma^{\prime}$ in back-scattered mode, it must be enriched in refractory elements, which in this case should be $\mathrm{Ta}$ [denuded in $\mathrm{Re}$, c.f. Figure 5(d)]. EDS point measurements were conducted 


\section{Refractory-rich
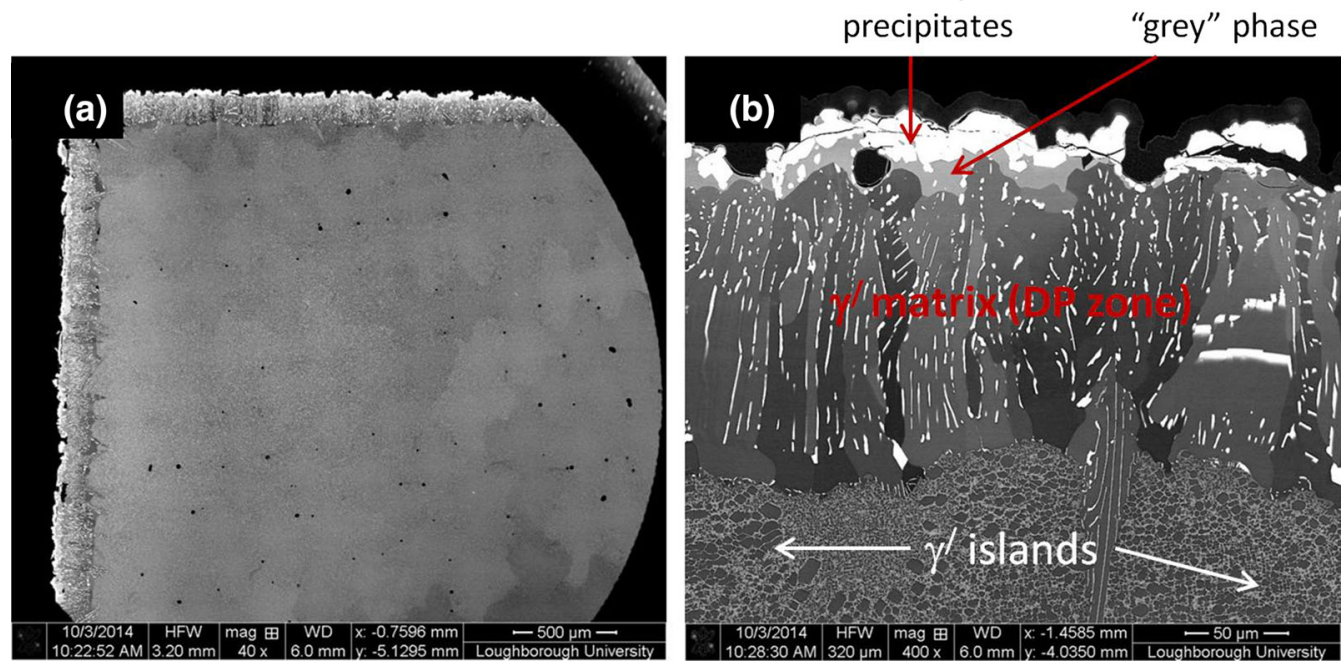

Fig. 4 - (a) Low-magnification back-scattered electron image (BEI) of the entire sample cross section showing discontinuous precipitation zone after isothermal hold at $1623 \mathrm{~K}\left(1350{ }^{\circ} \mathrm{C}\right)$ for $14 \mathrm{~h}$, (b) high-magnification BEI showing the detailed evolution of microstructures.
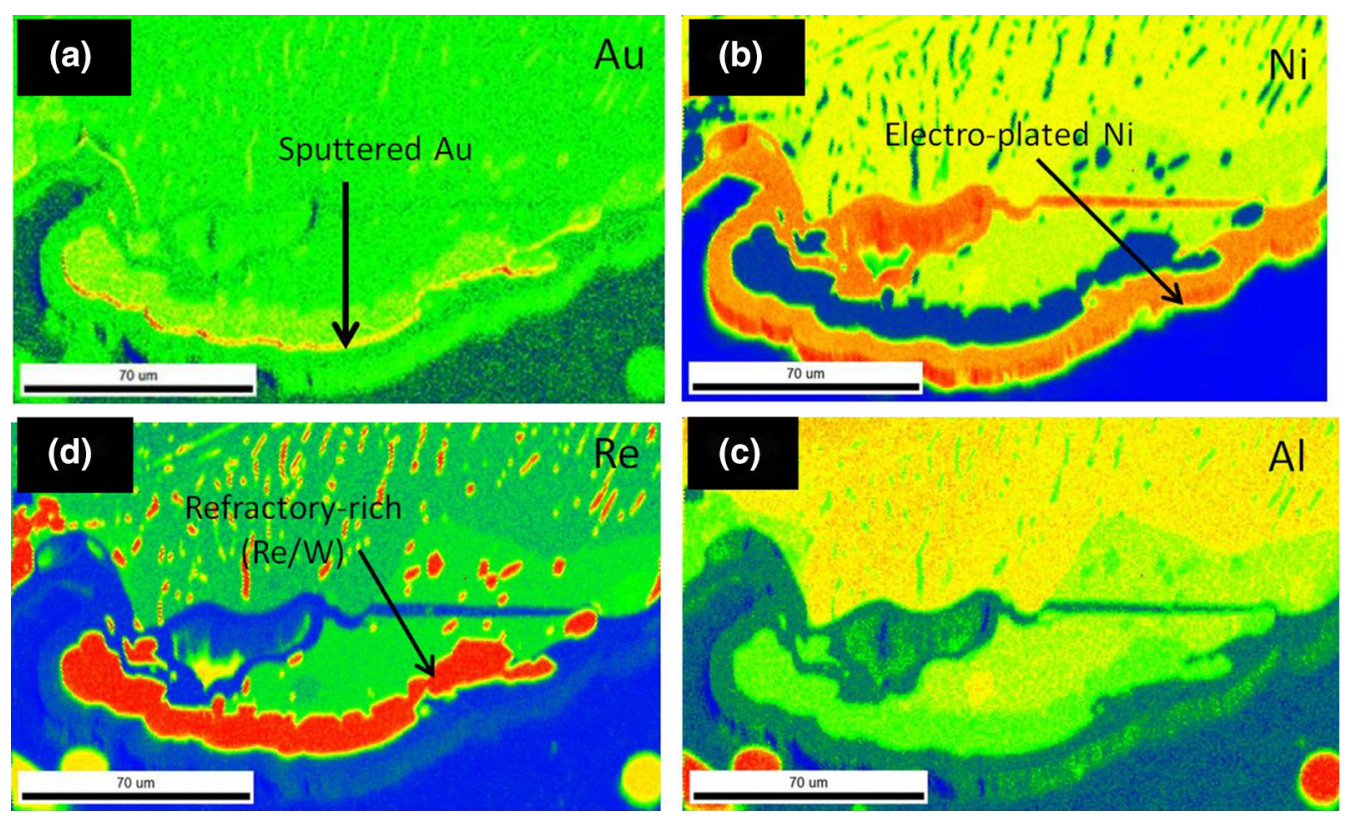

Fig. 5-Elemental EDS maps showing composition within the surface layers after isothermal hold at $1623 \mathrm{~K}\left(1350{ }^{\circ} \mathrm{C}\right)$ for $14 \mathrm{~h}:(a) \mathrm{Au},(b) \mathrm{Ni}$, (c) Al, (d) Re.

within this Al-denuded layer and also within the DP zone, where measurements in the latter case were only restricted to the $\gamma^{\prime}$ matrix and precluding the refractoryrich precipitate. The aim was to compare the solute partitioning within these layers (in atom fraction).

- Al-denuded layer [grey layer, c.f. Figure 4(b)]: $\frac{\mathrm{Ni}}{\mathrm{Al}}=6.78$ and $\frac{\mathrm{Al}}{\mathrm{Ta}}=1.32$,

- $\gamma^{\prime}$ (DP zone): $\frac{\mathrm{Ni}}{\mathrm{Al}}=4.88$ and $\frac{\mathrm{Al}}{\mathrm{Ta}}=3.84$,

- $\gamma$ ( $\gamma$-channels within $\gamma / \gamma^{\prime}$ morphology in homogenized alloy): $\frac{\mathrm{Ni}}{\mathrm{Al}}=26.24$ and $\frac{\mathrm{Al}}{\mathrm{Ta}}=7.17 .^{[19]}$

This clearly shows the presence of a Ta-enriched (Al-denuded) region beneath the $\mathrm{Re} / \mathrm{W}$ surface precipitates, where solute partitioning is distinct from both $\gamma$ and $\gamma^{\prime}$ phases. To definitively conclude that this is indeed the case, the phase map across a typical transverse section was derived using EBSD. In the phase map in Figure 6(b), the region in "red" corresponds to cubic $\gamma$ or $\gamma$ ' phase, since $\gamma$ and $\gamma^{\prime}$ phases cannot be independently distinguished in EBSD. On the other hand, any non-cubic phase such as the refractory-rich TCP phases remains unindexed and therefore black. Comparing the BEI in Figure 6(a) with the corresponding phase map in Figure 6(b) unequivocally demonstrates that this Al-denuded (Ta-enriched) phase is non-cubic and distinct from $\gamma$ and $\gamma^{\prime}$ [contained within the white curves in Figure 6(b)]. 


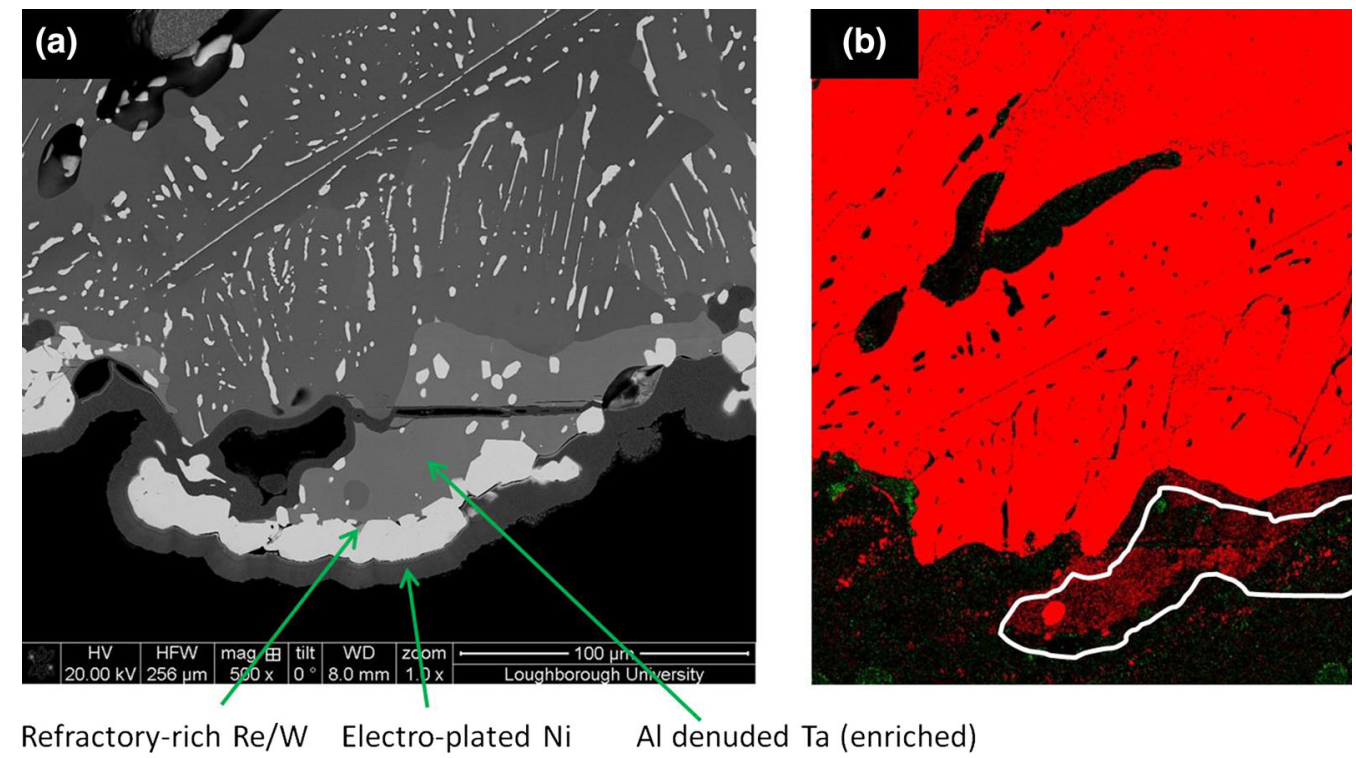

Fig. 6 - (a) BEI showing surface layer and (b) EBSD-derived phase map corresponding to isothermal hold at $1623 \mathrm{~K}\left(1350{ }^{\circ} \mathrm{C}\right)$ for $14 \mathrm{~h}$.

In summary, therefore, at temperatures approaching the solvus and during isothermal hold, there is dissolution of $\beta$-islands that existed during the initial stages of DP and in most cases the DP zone has extended into the surface.

\section{B. Development of the Microstructure Ahead of the Discontinuous Precipitation Cell}

Having considered the DP morphology, in this section, the interface of the DP zone and the substrate beyond will be analyzed. Figure 7(a) is a montage image corresponding to $1623 \mathrm{~K}\left(1350{ }^{\circ} \mathrm{C}\right)$ that extends further into the substrate to assess the depth to which any phase transformations might have occurred ahead of the DP interface. The BEI in Figure 7(b) focuses on the interface between the DP cell and the substrate, while that in Figure 7(c) corresponds to that within the bulk.

The following observations can be made:

(i) The coarse $\gamma^{\prime}$ morphology ahead of the DP zone extends to $\sim 150 \mu \mathrm{m}$ beyond the DP cell interface into the substrate and the $\gamma^{\prime}$ morphology is roughly globular in shape.

(ii) The $\gamma^{\prime}$ within the bulk (remote from the surface) shows the more regular cube-type morphology. However, the fine $\gamma^{\prime}$ morphology between abutting globular $\gamma^{\prime}$ is much less regular in shape, albeit their relative sizes are comparable $(\sim 1.5 \mu \mathrm{m}$ cube edge) to that within the bulk.

The nucleation and growth of $\gamma^{\prime}$ ahead of the DP zone will be accompanied by solute re-distribution within the surrounding region. In the following Sections III-B-2 and III-B-1, the temporal evolution of $\gamma^{\prime}$ and the accompanying segregation within the $\gamma$-channels will be quantitatively characterized in detail.
1. Elemental segregation within $\gamma$ phase

The nucleation and growth of $\gamma^{\prime}$ is accompanied by rejection of $\mathrm{Cr}, \mathrm{W}$, and $\mathrm{Re}$ to the surrounding $\gamma$ phase, since these elements have very limited solubility in $\gamma^{\prime}$. As observed in Figure 7(b), there is an irregular $\gamma / \gamma^{\prime}$ morphology in the region of interest ahead of the DP cell. Therefore, any form of composition measurement using microprobe analyses using SEM will be seriously biased owing to the "volume-averaging" effects. ${ }^{[20]} \mathrm{A}$ more appropriate method that is less susceptible to these effects would be the measurement of composition within the individual $\gamma$-channels themselves. Composition within $\gamma$-channels in the vicinity of the DP interface were compared with those in the bulk.

Figure 8(a) is a BEI that shows the region from where a TEM foil was extracted from the DP interface, where the surface deposited Pt-layer is observed. Figure $8(\mathrm{~b})$ is a dark-field STEM micrograph, which shows $\gamma^{\prime}$ (dark) precipitates and the $\gamma$-channel (bright) between. Spectra were acquired from regions within the micrograph and these are indicated. Also, "flecks" are observed within the $\gamma$-channel [Figure 8(b)] and these constitute "secondary" $\gamma^{\prime}$ that have precipitated within the channel. To ensure that the acquired spectra are not affected by the choice of regions, a spectrum was acquired from the entire width of the channel in Figure 8(b), i.e., spectrum no. 25. These are presented in Figures 9(a) and (b), where a comparison is made between spectrum 4 (red outline) and spectrum 25 (yellow), where spectrum no. 4 is a subset of a region within the channel [Figure 8(b)]. Also, given that Ta, $\mathrm{W}$, and Re energy peaks suffer significant overlap, the "true" location of a Re and $\mathrm{W}$ peak (i.e. $\mathrm{keV}$ ) is indicated in Figures 9(a) and (b), respectively, and corresponds to the region shaded in "brown." The following observations can be made: 


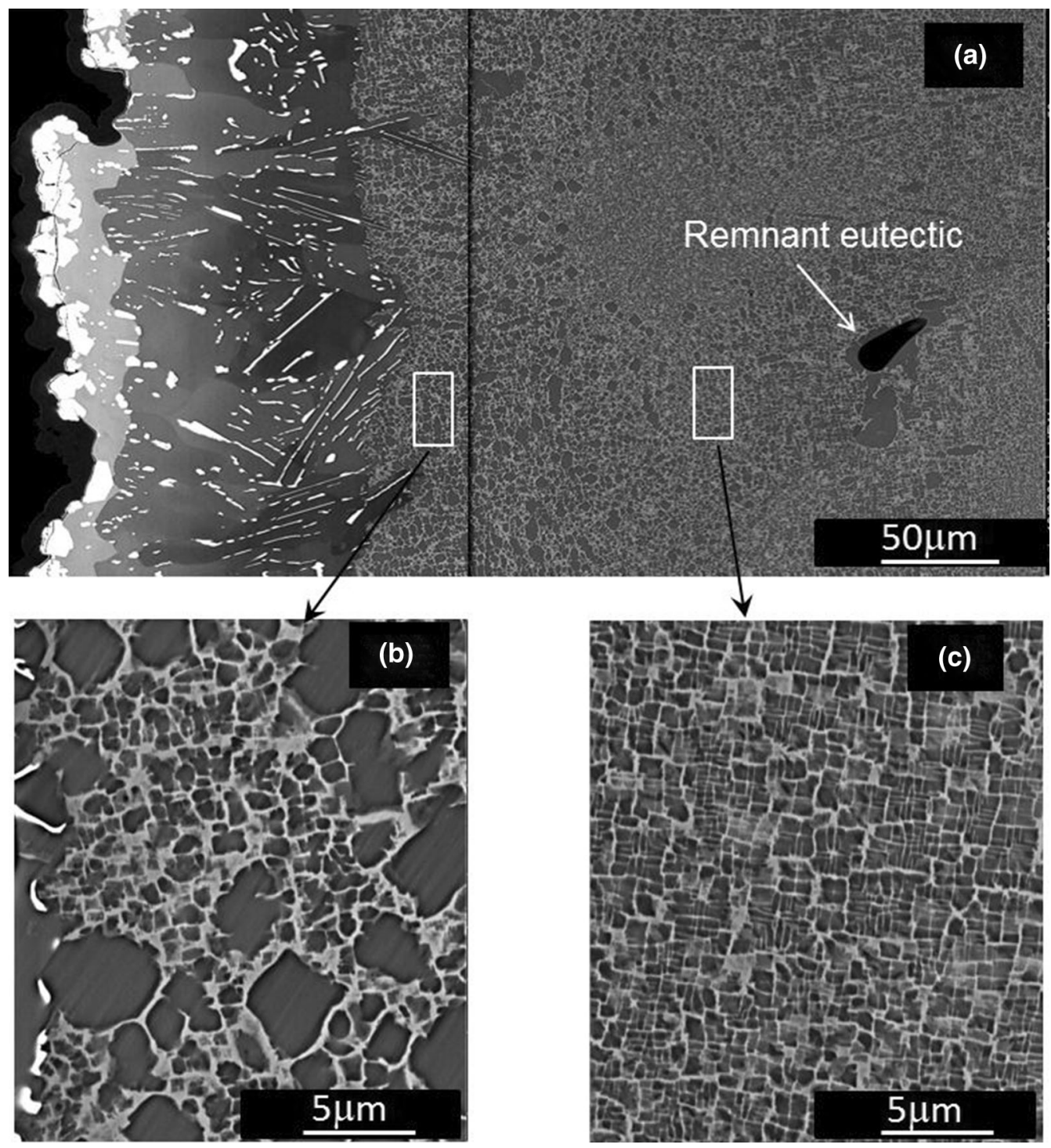

Fig. 7-Back-scattered electron images showing microstructure developing ahead of the discontinuous precipitation zone: (a) Montaged image, (b) High-magnification image showing interface with the DP zone, (c) High-magnification image in the bulk.

(iii) There is no difference between the two spectra, i.e., the red and yellow regions overlap. Therefore, the secondary $\gamma^{\prime}$ within the $\gamma$-channel is not affecting the measurement.

(iv) When the measured spectra are compared with the keV location of $\mathrm{W}$ and $\mathrm{Re}$ peaks, it is clear that the greatest contribution to the measured spectra arises from Re. This is because the $\mathrm{keV}$ location of the Re peak is centered close to the measured peak in the spectra, unlike W.

(v) The $\gamma$-channel is primarily segregated in $\mathrm{Re}, \mathrm{W}$, $\mathrm{Cr}$, and to a lesser extent Co and Mo compared to $\gamma^{\prime}$. It should be mentioned that the $\mathrm{Cu}$ peak arises from interaction with the $\mathrm{Cu}$ grid used for the TEM foil and should be ignored.

Likewise, a similar measurement was carried out using a TEM foil extracted from within the bulk but not included here for the sake of brevity. The overlaid spectra corresponding to $\gamma$-channels at the surface and in the bulk is presented in Figure 10. The measured composition is particularly sensitive to thickness (arising from the absorption of X-rays) and to a lesser degree density variations within a sample. Therefore, for an accurate comparison of spectra from two foils, it is imperative to use foils of similar thickness. Accordingly, great care was taken to ensure that both lifted out samples were of very similar thicknesses. The role of thickness can be quantitatively expressed by the ratio of the $\mathrm{K}$ and $\mathrm{L}$ peaks (a relatively lower $\mathrm{L}$ peak indicates thicker sample, i.e., increased X-ray absorption).

The following observations can be made:

(vi) There is a similar $\mathrm{Ni}-\mathrm{K} / \mathrm{Ni}-\mathrm{L}$ peak ratio in both cases. This indicates the absence of significantly different absorption effects between the two 

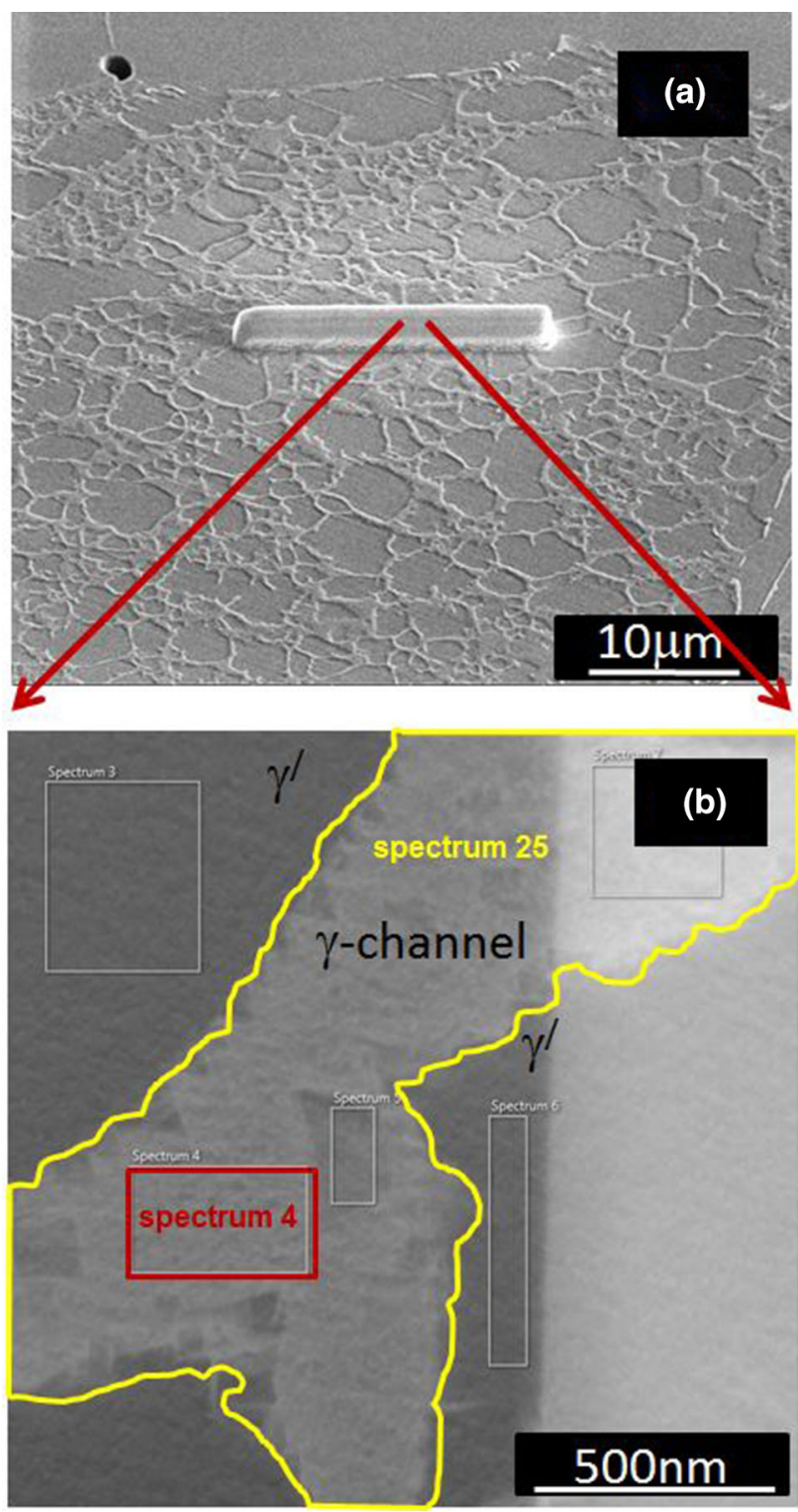

Fig. 8- (a) Back-scattered electron image showing region just ahead of the DP zone from where the TEM foil was extracted, $(b)$ Darkfield scanning transmission electron (STEM) image showing $\gamma$-channel between adjacent $\gamma^{\prime}$ precipitates.

samples and categorically emphasizing the validity of the comparison of compositions in the two samples (owing to similar thickness of the two foils).

(vii) The $\gamma$-channels at the surface are more segregated in $\mathrm{Cr}, \mathrm{W}, \mathrm{Re}$, and Mo compared to the channels within the bulk. Quantitative analyses of the spectra give a segregation ratio $(\mathrm{R})$ for the principal elements; $R^{\mathrm{Cr}}=1.6, R^{\mathrm{W}}=1, R^{\mathrm{Re}}=1.3$, where $R=\frac{\text { composition in } \gamma \text {-channel at surface }}{\text { composition in } \gamma \text {-channel in bulk }}$.

It is important to emphasize that notwithstanding such an approach in deriving reliable composition in a multi-component system significant errors can arise, and therefore, a comparison of spectra has been made rather than an absolute quantification.
2. Time-based evolution of $\gamma^{\prime}$ ahead of the discontinuous precipitation cell interface

The mole-fraction of $\gamma^{\prime}$ was measured during temperature ramps up to $1623 \mathrm{~K}\left(1350{ }^{\circ} \mathrm{C}\right)$ and during subsequent isothermal hold by measuring the diffracted intensity of the (110) peaks. The original single crystal gave rise to only a single spot on the area detector used for these measurements, with the (110), (220), and (330) peaks overlapping at the same location. The (110) and (330) peaks arise exclusively from the super-lattice of the $\gamma^{\prime}$ phase, while the (220) peak has contributions from both $\gamma$ and $\gamma^{\prime}$ phases. Figure 11 shows the measured lattice spacing for the (110) and (220) peaks during the heating stage, where the different shapes of the (110) and (220) curves arise from the different thermal expansion of the individual phases. The close agreement between these curves for different heating runs confirms the absence of any significant thermal lag during heating.

In using the intensity of a diffraction peak to estimate the phase fraction, various effects must be considered.

- First, a proportionality constant must be determined that relates the absolute intensity to the volume fraction of the diffracting phase. This incorporates the effects of the incident beam intensity, the structure factor of the diffracting plane, the total gage volume being measured and the absorption of the beam by the sample environment. The $\gamma^{\prime}$ molefraction as a function of temperature can be determined using thermodynamic software. Accordingly, we use a $\gamma^{\prime}$ mole-fraction of 0.75 for temperatures under $1073 \mathrm{~K}\left(800^{\circ} \mathrm{C}\right)$.

- Second, as the temperature rises, the intensity of a diffracted peak reduces because of the thermal motion of atoms from their ideal lattice positions. This effect is quantified by the Debye-Waller factor $e^{-2 \mathrm{~W} \cdot[21]}$

$$
W=8 \pi^{2}\left\langle u^{2}\right\rangle\left(\frac{\sin \theta}{\lambda}\right)^{2}
$$

where $\left\langle u^{2}\right\rangle$ is the time-averaged mean squared displacement of atoms from their ideal lattice position, $2 \theta$ is the diffraction angle of $90 \mathrm{deg}$, and $\lambda$ is the neutron wavelength. The temperature of dependence of $\left\langle u^{2}\right\rangle$ for $\gamma$ and $\gamma^{\prime}$ phases limits the utility of using the (220) peak intensity in determining the $\gamma / \gamma^{\prime}$ molefraction ratio. However, the wavelength dependence of the Debye-Waller factor can instead be used to deduce the temperature dependence of $\left\langle u^{2}\right\rangle$ for just the $\gamma^{\prime}$ phase. By considering the decrease in diffraction intensity with temperature for the (110) and (330) peaks, which correspond to different wavelengths but both arising only from diffraction of $\gamma^{\prime}$, it is possible to derive the parameters for a model relating $\left\langle u^{2}\right\rangle$ to temperature, provided limited change in mole-fraction occurs over the temperature range considered.

- By assuming a linear relation between $\left\langle u^{2}\right\rangle$ and absolute temperature and by calibrating with (110) and (330) measured intensities from room temperature to $1073 \mathrm{~K}\left(800{ }^{\circ} \mathrm{C}\right.$ ) (where the change in 

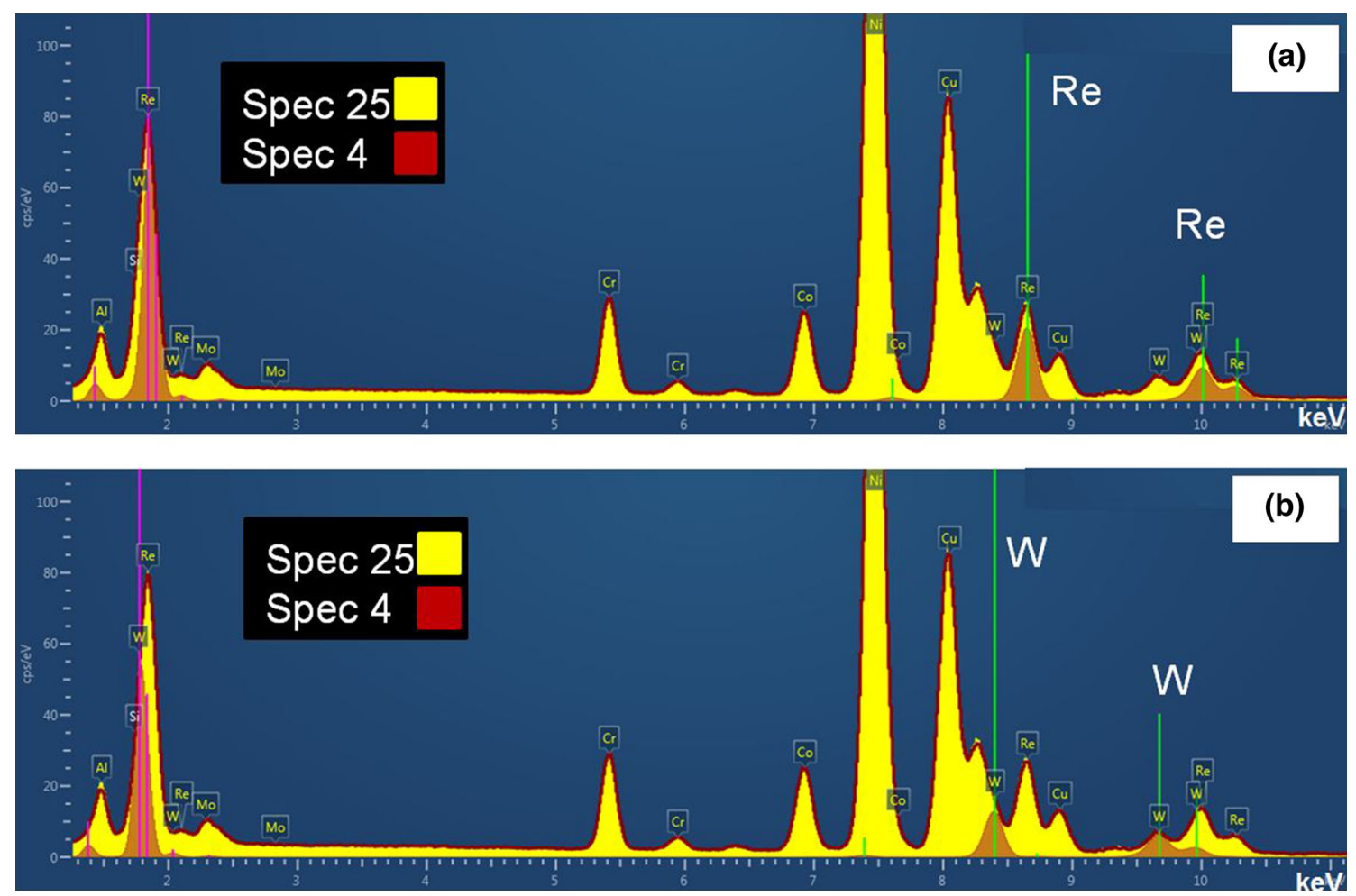

Fig. 9-Spectra obtained from two regions [indicated in Fig. 8(b)] within the $\gamma$-channel. Also superimposed are the (a) Re and (b) W peaks at the corresponding $\mathrm{keV}$.

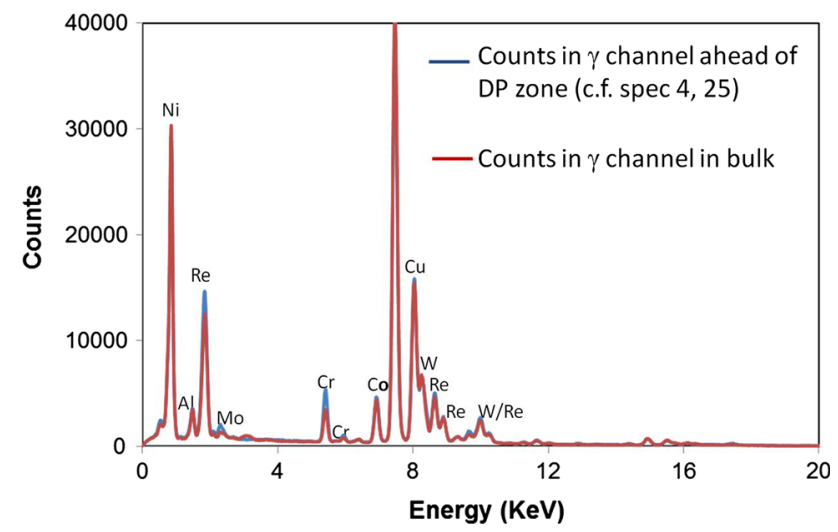

Fig. 10-Spectra obtained from $\gamma$-channel corresponding to the interface with the DP zone and also within the bulk [c.f. Figs. 7(b) and (c), respectively].

mole-fraction over the temperature range is small) it can be shown that the (110) peak would retain 88.7 pct of its room temperature intensity at $1623 \mathrm{~K}$ $\left(1350{ }^{\circ} \mathrm{C}\right)$, compared to just 39.0 pet for the $(330)$ peak.

Hence, despite the use of a simple linear relation for this purpose, this result is sufficient to justify using solely the (110) peak intensity to estimate $\gamma^{\prime}$ mole-fraction. Figure 12 shows the calculated variation in $\gamma^{\prime}$ mole-fraction as a function of isothermal hold at the set temperature of $1623 \mathrm{~K}\left(1350^{\circ} \mathrm{C}\right)$. After applying the Debye-Waller

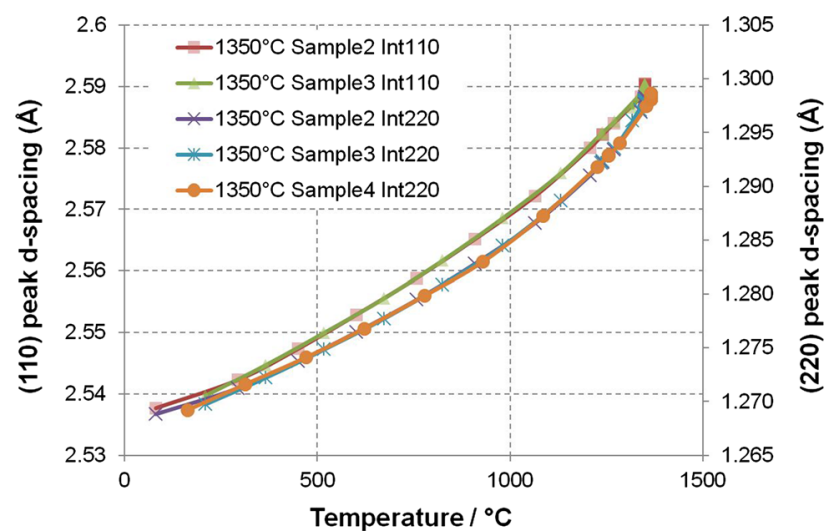

Fig. 11-Measured lattice spacing for the (110) and (220) peaks during the heating stage. Different shapes of the (110) and (220) curves arise from the different thermal expansion of the individual $(\gamma$ and $\left.\gamma^{\prime}\right)$ phases.

correction, the $\gamma^{\prime}$ fraction is found to remain constant until $1173 \mathrm{~K}\left(\sim 900{ }^{\circ} \mathrm{C}\right)$, and between $1273 \mathrm{~K}$ and $1473 \mathrm{~K}$ $\left(1000{ }^{\circ} \mathrm{C}\right.$ and $\left.1200{ }^{\circ} \mathrm{C}\right)$ the decrease in $\gamma^{\prime}$ follows the thermodynamic calculation results, which again corroborates our method of analyses. On reaching the isothermal hold temperature of $1623 \mathrm{~K}\left(1350^{\circ} \mathrm{C}\right)$, the quantity of $\gamma^{\prime}$ is found to increase again from 4 pct to about 7.5 pct. It is important to emphasize that this measurement exclusively refers to $\gamma^{\prime}$ that has the same crystallographic orientation as the substrate and thus contributing to the diffracted (110) peak. Therefore, this only pertains to the $\gamma^{\prime}$ that has nucleated and grown ahead of the DP 
interface and also to the remnant $\gamma^{\prime}$ present given that the solvus temperature is $1635 \mathrm{~K}\left(1362^{\circ} \mathrm{C}\right)$. It categorically precludes $\gamma^{\prime}$ within the DP zone.

\section{DISCUSSION}

\section{A. Phenomenological Evolution of the Discontinuous Precipitation Morphology}

The phenomenological evolution of the discontinuous precipitation morphology can be illustrated using the schematic diagram in Figure 13.

- Figure 13(a) - Initial vaporization of (1) Ni, Co, and $\mathrm{Cr}$ from $\gamma$ phase and (2) Ni from $\gamma^{\prime}$ occurs from the surface, as these elements are characterized by high vapor pressures. ${ }^{[22]}$ However, in non-ideal solid solutions, interactions exist between the elements, which alter the chemical potential of the species and which alters the elemental vapor pressure in solid solution. This can account for significantly reduced vaporization of $\mathrm{Al}$ from $\gamma$ phase and also reported in $^{[23]}$. Vaporization is also dependent on the "local"

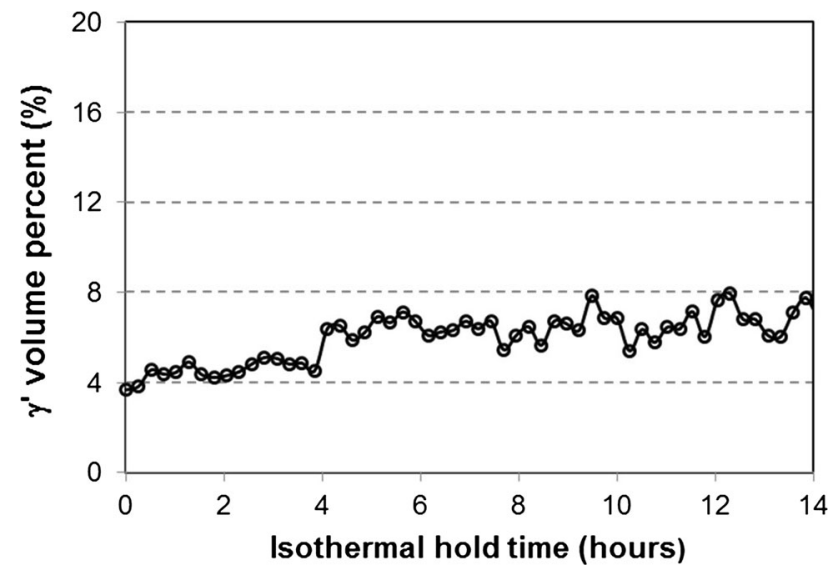

Fig. 12-Calculated variation in $\gamma^{\prime}$ volume percent as a function of isothermal hold at $1623 \mathrm{~K}\left(1350^{\circ} \mathrm{C}\right)$ (time $=0$ corresponds to the start of isothermal hold) conditions in the vicinity of the surface, i.e., the presence of a carrier gas such as Ar will reduce the vaporization rate compared to a "perfect" vacuum. However, as observed in our experiments vaporization does occur despite the presence of Ar, Figures 3(a) and (b). There is limited inter-diffusion from the substrate, since diffusion is primarily grain boundary controlled well below the solvus temperature $\left.T \sim 1473 \mathrm{~K}\left(T \sim 1200{ }^{\circ} \mathrm{C}\right)\right]$.

- Figure 13(b):

- The increased vacancy concentration that arises must be annihilated either through formation of pores and/or dislocation climb. In the noticeable absence of pores, the latter is dominant. The resulting surface strain results in re-crystallization. A similar re-crystallization phenomenon arising from element loss has also been reported in the case of oxidation ${ }^{[24]}$ and in the case of Kirkendall-diffusion-based deformation in diffusion couples. ${ }^{[25]}$

- Loss of Ni leads to dissolution of $\gamma$ phase and stabilization of $\gamma^{\prime}$. The excess $\mathrm{W}$ and Re result in precipitation of refractory-rich TCP phases at the grain boundary and further growth occurs by short-circuit diffusion along the boundary. This constitutes the DP zone.

- Figure 13(c):

- Further Ni vaporization leads to dissolution of $\gamma^{\prime}$ phase and nucleation of polycrystalline $\beta$ grains, since no orientation relationship between $\mathrm{B} 2\left(\beta\right.$ phase) and $\left[\mathrm{Ll}_{2}\left(\gamma^{\prime}\right)\right.$ or A1 $\left.(\gamma)\right]$. Moreover, since $\beta$ has no solubility for Ta, simultaneous diffusion of Ta occurs from the surface into the substrate. Vaporization of Al now also occurs but is significantly lower than that of $\mathrm{Ni}$ [evidence of $\beta$-condensate in Figure 3(a)].

- Inter-diffusion with the substrate leads to growth of the DP cell. Once a continuous layer of $\beta$ forms at the surface, this marks the end of the initial stages of DP.

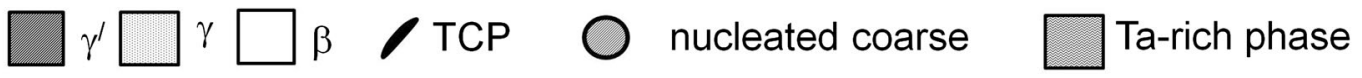

$\sim 1200^{\circ} \mathrm{C}$

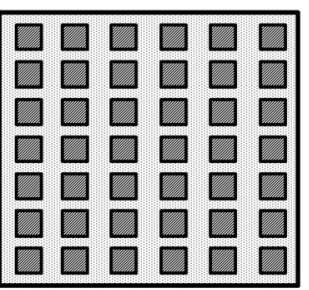

(a) $\sim 1250^{\circ} \mathrm{C}$

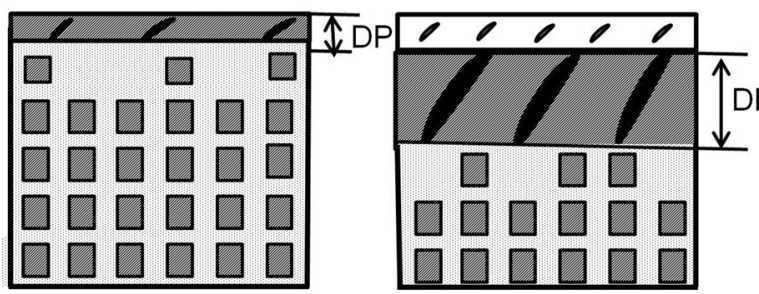

(b) (c) $\sim 1350^{\circ} \mathrm{C}$

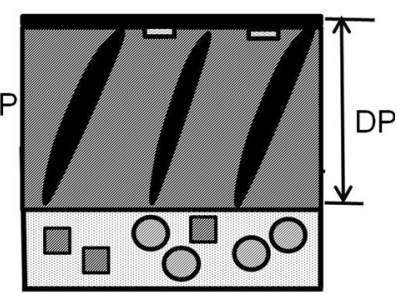

(d)

Fig. 13 - Schematic diagram showing evolution of DP zone and morphology ahead of DP zone during solution heat treatment. 


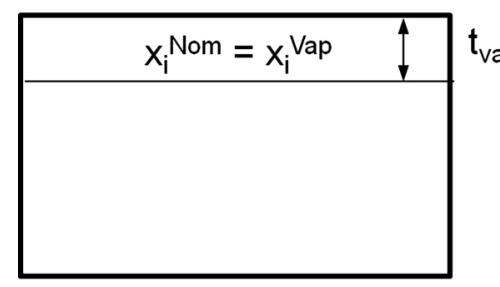

(a)

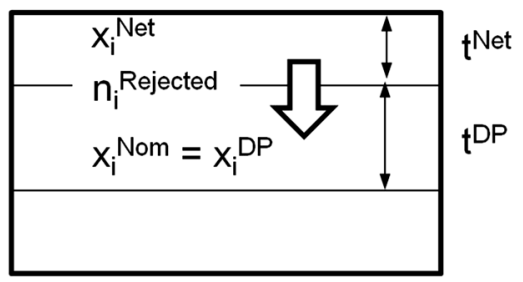

(d)

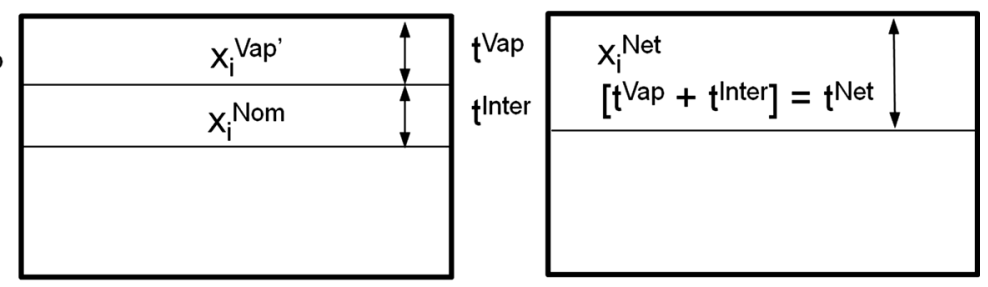

(c)

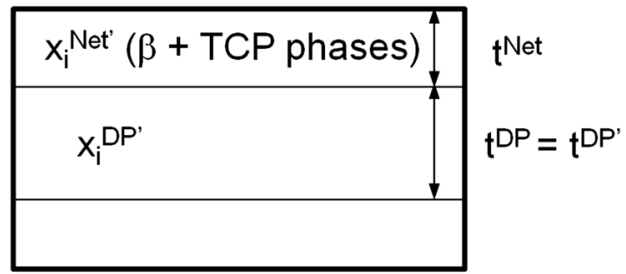

(e)

Fig. 14-Schematic diagram showing composition evolution of DP zone and in the morphology ahead of DP zone during solution heat treatment.

- Figure 13(d):

- Vaporization of $\mathrm{Ni}$ and $\mathrm{Al}$ now occurs from the $\beta$ layer at higher temperatures $\left(T>1300{ }^{\circ} \mathrm{C}\right)$ approaching the solvus [please note that these experiments, i.e., Figure 4(a) corresponds to solutioning in vacuum; furnace pressure $\left.\sim 10^{-8} \mathrm{~atm}\right]$. The main factor that affects the rate of vaporization in vacuum $\left(\mathrm{p}_{\mathrm{O} 2}<<<1\right)$ is the presence of a dense stable oxide such as $\mathrm{Al}_{2} \mathrm{O}_{3}$. $\beta$ $\mathrm{NiAl}$ is a Group III former, where $\alpha-\mathrm{Al}_{2} \mathrm{O}_{3}$ is the stable oxide even at very low $\mathrm{O}_{2}$ partial pressures and characterized with significantly retarded growth kinetics, unlike $\mathrm{NiO}$ or spinels. ${ }^{[26]}$

- It is clear from Figures 4(a) and (b) that vaporization of $\mathrm{Ni}$ and $\mathrm{Al}$ from $\beta$ and $\gamma^{\prime}$ is extensive. The other elements also having high vapor pressures; $\mathrm{Co}$ and $\mathrm{Cr}$, however, have very limited solubility in $\beta$ and $\gamma^{\prime} \cdot{ }^{[22]}$ The dissolution of $\beta$ and $\gamma^{\prime}$ in the vicinity of the surface (vaporization of $\mathrm{Ni}$ and $\mathrm{Al}$ ) therefore leads to the growth of $\mathrm{Re} / \mathrm{W}$ precipitates, which existed in the DP zone. On the other hand, diffusion of $\mathrm{Ta}$ occurs away from the surface. The extent of Ta diffusion dictates the nucleation of the Ta-enriched phase beneath the $\mathrm{Re} / \mathrm{W}$ precipitates that is observed sporadically.

- Also, since vaporization of $\mathrm{Ni}$ is greater than that of $\mathrm{Al},{ }^{[27]}$ volume diffusion of $\mathrm{Al}$ also occurs from the surface layers into the substrate beyond the grain boundary (i.e., ahead of the DP zone). This leads to nucleation of $\gamma^{\prime}$ within $\gamma$ phase ahead of the DP zone and subsequent and growth of $\gamma^{\prime}$.

In the following sections, both the initial and later stages of discontinuous precipitation will be considered in detail.

\section{B. Initial Stages of Discontinuous Precipitation [c.f. Figures 13(a) Through (c)]}

The initial stage of DP terminates with the formation of a continuous layer of $\beta$ across the surface [Figure 13(c)]. Beneath the $\beta$ layer is a DP layer, i.e., $\left[\gamma^{\prime}+\right.$ needle-like TCP $]$. The driving force for growth of the DP zone is calculated using the commercial software JMatPro ${ }^{T M} .{ }^{[28]} \mathrm{JMatPro}^{\mathrm{TM}}$ uses a multi-component thermodynamic database, Ni-Data developed by ThermoTech Ltd (UK).

Let vaporization occur from a layer of thickness, $t^{\mathrm{Vap}}$ (vaporization layer) corresponding to nominal $x_{i}^{\text {Nom }}$ [Figure 14(a)]. Following vaporization, the total number of moles of elements $i$ in the vaporization layer changes from $n_{\mathrm{i}}^{\text {Vap }}$ before vaporization to $n_{i}^{\text {Vap' }}$ and the composition (mole-fraction) changes to $x_{i}^{\mathrm{Vap}^{\prime}}$ [Figure 14(b)]:

$$
n_{i}^{\mathrm{Vap} \prime}=\alpha_{i} \cdot n_{i}^{\mathrm{Vap}},
$$

where $\alpha_{i}$ is the fraction of element retained within the surface layer (not vaporized) with thickness, $t^{\text {Vap }}$. Simultaneous inter-diffusion also occurs with the substrate of thickness, $t^{\text {Inter }}$. Here perfect mixing is assumed between vaporization and substrate layers and the thickness of the resultant ("net") layer after diffusion is $t^{\mathrm{Net}}=\left[t^{\mathrm{Vap}}+t^{\text {Inter }}\right]$.

Therefore, the number of moles of element " $i$," within this "net" layer is [Figure 14(c)]

$$
n_{i}^{\mathrm{Net}}=n_{i}^{\mathrm{Vap}^{\prime}}+n_{i}^{\mathrm{Inter}} .
$$

Assuming constant molar volume, the total number of moles of elements in a layer is proportional to the layer thickness; $n_{i}=x_{i} \cdot t$, where $x_{i}$ is mole-fraction. Therefore, within the "net" layer the composition is 


$$
x_{i}^{\mathrm{Net}}=\frac{n_{i}^{\mathrm{Net}}}{\sum_{i} n_{i}^{\mathrm{Net}}}=\frac{\alpha_{i} \cdot t^{\mathrm{Vap}} x_{i}+t^{\mathrm{Inter}} x_{i}}{\sum_{i}\left(\alpha_{i} \cdot t^{\mathrm{Vap}} x_{i}+t^{\text {Inter }} x_{i}\right)} .
$$

The "net" layer transforms to $\beta$ phase and, moreover, sporadic precipitation of TCP phase is also observed in the "net" layer. Therefore, elements having no solubility in $\beta$ and TCP phases are rejected into the substrate beneath [Figure 14(d), please note that the number of moles rejected is indicated in the figure]. The number of moles of element $i$ rejected from the "net" layer, $n_{\mathrm{i}}^{\text {Rejected }}$, into the substrate beneath having thickness, $t^{\mathrm{DP}}$, is given by

$$
n_{i}^{\text {Rejectd }}=n_{i}^{\mathrm{Net}}-t^{\mathrm{Net}}\left[f^{\beta} \cdot x_{i}^{\beta}+f^{\mathrm{TCP}} \cdot x_{i}^{\mathrm{TCP}}\right],
$$

where $f^{\beta}$ and $f^{\mathrm{TCP}}$ are the phase fractions of $\beta$ phase and TCP phase, respectively, and $x_{i}^{\beta}$ and $x_{i}^{\mathrm{TCP}}$ are the mole-fraction of element $i$ in $\beta$ phase and TCP phase, respectively. Perfect mixing is now considered between these rejected elements and a layer of substrate with thickness, $t^{\mathrm{DP}}$ leading to the evolution of the DP cell. The total number of moles of element, $i$, in the DP cell, $n_{i}^{\mathrm{DP}^{\prime}}$, after mixing is given by

$$
n_{i}^{\mathrm{DP}^{\prime}}=n_{i}^{\mathrm{DP}}+n_{i}^{\text {Rejected }},
$$

where $n_{i}^{\text {DP }}$ is the total number of moles in the DP layer (with nominal composition, $x_{i}^{\mathrm{Nom}}$ ) before receiving the rejected atoms. Substituting Eqs. [2] through [5] into Eq. [6] and after considering the proportional relationship between $n$ and $t$, the composition of the DP cell can then be calculated as [Figure 14(e)]:

$$
\begin{aligned}
x_{i}^{\mathrm{DP}^{\prime}} & =\frac{n_{i}^{\mathrm{DP}^{\prime}}}{\sum_{i} n_{i}^{\mathrm{DP}}} \\
& =\frac{t^{\mathrm{DP}} \cdot x_{i}^{\mathrm{Nom}}+t^{\mathrm{Net}} \cdot\left(x_{i}^{\mathrm{Net}}-f^{\beta} \cdot x_{i}^{\beta}-f^{\mathrm{TCP}} \cdot x_{i}^{\mathrm{TCP}}\right)}{\sum_{i}\left[t^{\mathrm{DP}} \cdot x_{i}^{\mathrm{Nom}}+t^{\mathrm{Net}} \cdot\left(x_{i}^{\mathrm{Net}}-f^{\beta} \cdot x_{i}^{\beta}-f^{\mathrm{TCP}} \cdot x_{i}^{\mathrm{TCP}}\right)\right]} .
\end{aligned}
$$

From Eq. [7], the phase evolution as a function of temperature can then be determined within the DP cell. The parameters for the calculation were estimated from the experimental results following Figure 3(a).

(a) The width of the $\beta$ layer and the $\left[\gamma^{\prime}+\right.$ non-needle TCP] layer is $\sim 5 \mu \mathrm{m}$ each; therefore, $t^{\mathrm{Net}}=$ $\left[t^{\mathrm{Vap}}+t^{\text {Inter }}\right] \approx 10 \mu \mathrm{m}$.

(b) $\beta$ phase forms within the "net" layer and therefore for a "net" layer thickness of $10 \mu \mathrm{m}$, a typical range, $0.2 \leq f^{\beta} \leq 0.4$ is considered. Also from Figure 3(a), the fraction of TCP within the $\beta$ layer is $0.1 \leq f^{\mathrm{TCP}} \leq 0.3$, from an area fraction measure.

(c) The thickness of the DP cell $\left[\gamma^{\prime}+\right.$ needle TCP $]$ is approximately $20 \mu \mathrm{m} ; t^{\mathrm{DP}} \approx 20 \mu \mathrm{m}$.

The DP zone comprises TCP phases within a $\gamma^{\prime}$ matrix; therefore, the choice of $\alpha_{i}$ (fraction retained) should yield a composition that shows a significantly lowered or absence of $\gamma$ phase. For the parameters chosen in (a), (b), and (c), the only possible range for $\alpha_{\mathrm{Ni}}$ and $\alpha_{\mathrm{Al}}\left[\alpha_{\mathrm{Co}}=\alpha_{\mathrm{Cr}}=0\right.$, given mole-fraction $<0.03$ and $\alpha_{i}=1$ for all other elements] are $\alpha_{\mathrm{Ni}} \approx 0$ and $\alpha_{\mathrm{Al}} \approx 1$. Otherwise, increasing fraction of $\gamma$ is obtained from the calculations using JMatPro ${ }^{\mathrm{TM}}{ }_{\text {, }}{ }^{[2]}$ which is not consistent with the observed microstructure in Figures 3(a) and (b). This is also supported by experimental data-for Al compositions less than $40 \mathrm{~mol}$ pet in $\beta$ phase, the partial pressure of $\mathrm{Ni}$ and $\mathrm{Al}\left(\mathrm{p}_{\mathrm{Ni}}\right.$ and $\left.\mathrm{p}_{\mathrm{Al}}\right)$ over the alloy are $\sim 10^{-4} \mathrm{~atm}$. However, the activity of $\mathrm{Al}\left(\mathrm{a}_{\mathrm{Al}}\right) \sim 10^{-4}$ is three-orders of magnitude lower than that for $\mathrm{Ni}\left(\mathrm{a}_{\mathrm{Ni}}\right) \sim 10^{-1}$ and which is therefore consistent with the assumption that $\mathrm{Ni}$-loss by vaporization exceeds that for Al. ${ }^{[27]}$

The evolution of phases corresponding to $x_{i}^{\mathrm{DP}^{\prime}}[c . f$. Eq. 7] was determined at three representative temperatures where volume diffusion is minimal, i.e., $1503 \mathrm{~K}$, $1533 \mathrm{~K}$, and $1563 \mathrm{~K}\left(1230{ }^{\circ} \mathrm{C}, 1260{ }^{\circ} \mathrm{C}\right.$, and $\left.1290{ }^{\circ} \mathrm{C}\right)$. The results are listed in Table II, which shows that this is predominantly $\gamma^{\prime}+\mathrm{P}$ phase $(\gamma$ phase $<<1)$. The reaction for the formation of $\mathrm{DP}^{\prime}$ following Eqs. [5] and [6] can be written as $\left[\gamma+\gamma^{\prime}\right]_{\mathrm{DP}}+i \rightarrow\left[\gamma^{\prime}+\mathrm{P} \text { phase }\right]_{\mathrm{DP}^{\prime} \text {, }}$ where $i$ stands for the rejected elements, and "DP" refers to layer with nominal composition, $x_{i}^{\text {Nom }}$ before receiving rejected elements, c.f. Eq. [5] and transforming to $\mathrm{DP}^{\prime}$. The free energy change is calculated per mole of alloy with composition, $x_{i}^{\mathrm{DP}}$.

$$
\begin{aligned}
\Delta G= & G\left(\mathrm{DP}^{\prime}\right)-\left[f^{\mathrm{DP}} \sum_{i} \mu_{i}^{\mathrm{DP}} x_{i}^{\mathrm{DP}}\right. \\
& \left.+\sum_{i} \mu_{i}^{\text {Rejected }}\left(x_{i}^{\mathrm{DP}^{\prime}}\right) f_{i}^{\text {Rejected }}\right] .
\end{aligned}
$$

The 2nd term within square brackets in Eq. [8a] contains all elements $i$, rejected from the "net" layer and since the calculations are per mole of alloy with composition, $x_{i}^{\mathrm{DP}^{\prime}},\left[f^{\mathrm{DP}}+\sum f_{i}^{\text {Rejected }}=1\right]$, ( since $x_{i}^{\text {Rejected }}=1$ ). These two entities need to be considered separately, since the chemical potential of element $i$ in $\gamma$ or $\gamma^{\prime}$ phase in DP $\neq$ chemical potential of the rejected element, $i$. Rather, chemical potential of rejected element, $i=$ chemical potential of element $i$ in $\gamma$ or $\gamma^{\prime}$ or TCP phase in $\mathrm{DP}^{\prime}$, as seen in Eq. [8a].

The Gibbs free energy corresponding to alloy with composition $\mathrm{x}_{\mathrm{i}}^{\mathrm{DP} \prime}$ (1st term in Eq. [8a]) is

$$
\begin{aligned}
G\left(\mathrm{DP}^{\prime}\right)= & f^{\prime} \sum_{i} \bar{\mu}_{i} x_{i}^{\gamma^{\prime}}+f^{\mathrm{P}-\text { Phase }} \sum_{i} \bar{\mu}_{i} x_{i}^{\mathrm{P}-\text { Phase }} \\
& +f^{\prime} \sum_{i} \bar{\mu}_{i} x_{i}^{\gamma},
\end{aligned}
$$

where $\bar{\mu}_{\mathrm{i}}$ is the elemental chemical potential in the products, $\left[f^{\prime}+f^{\text {P-Phase }}+f^{\prime}=1\right]$.

The principle on which Eqs. [8a] and [8b] are based can be easily illustrated using a binary system and the calculations can then be extrapolated for a multicomponent case. Figure 15 is a molar energy $(G v s \mathrm{x})$ diagram. For the binary case, the 1st, 2nd, and 3rd terms in Eq. [8a] are as indicated. Here, the average composition of the $\mathrm{DP}^{\prime}$ layer is $\mathrm{x}_{\mathrm{B}}^{\mathrm{DP}^{\prime}}$ and the chemical potential of the rejected $\mathrm{B}$ atoms $\left(\mu_{\mathrm{B}}^{\text {Rejected }}\right)$ is evaluated at this composition. In Figure 15, $\Delta G<0$, indicating a driving force for the reaction. The results from the calculations 


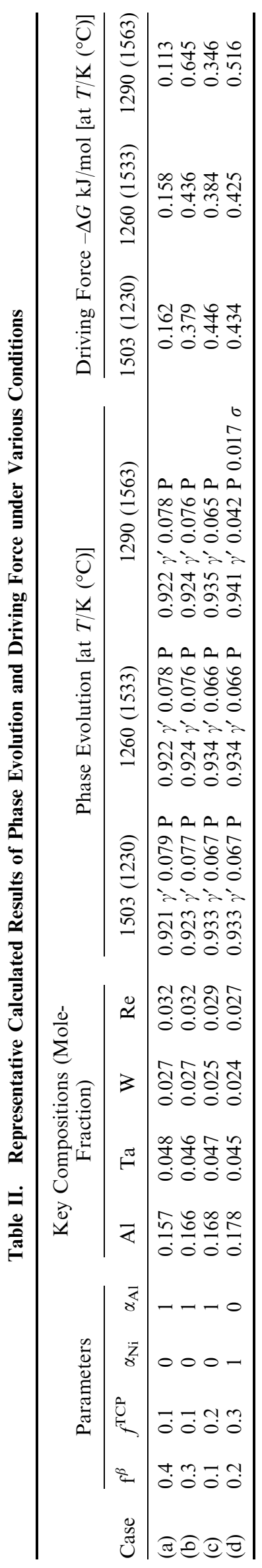

are listed in Table II, where $\Delta G<0(-\Delta G>0)$ indicates that there exists a driving force for growth of $\mathrm{DP}^{\prime}$, at any temperature.

In the case of grain boundary diffusion, the principal sink for the driving force arises from capillarity, i.e., the curvature of the needle-like TCP phases, since diffusion ahead of the boundary is negligible. The P-Phase needles grow with a convex curvature and some driving force must be consumed to overcome the pressure associated with the curvature and given by $2\left[\frac{\sigma V_{m}}{r}\right]$ per mole of P Phase, where $r$ is radius of curvature ( $\sim 0.1$ to $1 \mu \mathrm{m}), V_{\mathrm{m}}$ is molar volume $\left[V_{\mathrm{m}} \sim 6.59 \mathrm{~cm}^{3} / \mathrm{mol}\right.$ (for $\mathrm{Ni}$ )], and $\sigma$ is the high-angle grain boundary energy $\left(\sim 1.5 \mathrm{~J} \mathrm{~m}^{-2}\right) \cdot{ }^{[29]}$ This is estimated to be $\sim 0.002$ to 0.02$] \mathrm{kJ} \mathrm{mol}^{-1}$ of $\mathrm{DP}^{\prime}$ ( $\sim 0.1 \mathrm{~mol}$ of P Phase). Therefore, there is a minimal loss of driving force from capillarity and nearly all of the driving force is available to pull the grain boundary. Converting this to a force, which is given by $\left[\frac{\Delta G}{V_{m}}\right]$, where $V_{\mathrm{m}}$ is the molar volume; $F=1.5 \times 10^{-5}-10^{-4} \mathrm{~N} /\left[\mu \mathrm{m}^{2}\right.$ (of grain boundary) $]$.

\section{Latter Stages of Discontinuous Precipitation with Accompanying Loss of Driving Force [c.f. Figure $13(d)$ ]}

$\mathrm{Al}$ diffuses from the surface layers into the substrate. Moreover, since volume diffusion is predominant, $\mathrm{Al}$ also diffuses ahead of the grain boundary into the substrate. This results in a loss in driving force for DP. The increased Al composition ahead of the interface leads to nucleation and growth of $\gamma^{\prime}$, since the "local" solvus temperature is raised [Figures 7(a) and (b)].

To determine the net driving force, an approach similar to that presented in Section IV-B will be followed.

Accordingly, Eq. [6] can be modified as

$$
n_{i}^{\mathrm{DP}^{\prime}}=n_{i}^{\mathrm{DP}}+n_{\mathrm{Al}}^{\text {Rejected }},
$$

where $n_{i}^{\text {DP }}$ is the total number of moles with nominal composition, $x_{i}^{\text {Nom }}$, within a layer of thickness, $t^{\mathrm{DP}}$, before receiving the rejected $\mathrm{Al}$ atoms. Like in Eq. [7], the composition of this layer can then be calculated as

$$
\begin{gathered}
x_{i}^{\mathrm{DP}^{\prime}}=\frac{n_{i}^{\mathrm{DP}^{\prime}}}{\sum_{i} n_{i}^{\mathrm{DP}^{\prime}}}=\frac{t^{\mathrm{Nom}} \cdot x_{i}^{\mathrm{Nom}}}{\sum_{i} t^{\mathrm{Nom}} x_{i}^{\mathrm{Nom}}+n_{\mathrm{Al}}^{\text {Rejected }}} \quad i \neq A 1 \\
x_{i}^{\mathrm{DP}^{\prime}}=\frac{n_{i}^{\mathrm{DP}^{\prime}}}{\sum_{i} n_{i}^{\mathrm{DP}^{\prime}}}=\frac{t^{\mathrm{Nom}} \cdot x_{\mathrm{Al}}^{\mathrm{Nom}}+n_{\mathrm{Al}}^{\text {Rejected }}}{\sum_{i} t^{\mathrm{Nom}} x_{i}^{\mathrm{Nom}}+n_{\mathrm{Al}}^{\text {Rejected }}} \quad i=A 1 .
\end{gathered}
$$

The free energy change is then calculated per mole of $\mathrm{DP}^{\prime}$ :

$$
\begin{aligned}
\Delta G= & G\left(\mathrm{DP}^{\prime}\right)-\left[f^{\mathrm{DP}} \sum_{i} \mu_{i}^{\mathrm{DP}} x_{i}^{\mathrm{DP}}\right. \\
& \left.+\mu_{\mathrm{Al}}^{\text {Rejected }}\left(x_{\mathrm{Al}}^{\mathrm{DP}}\right) f_{\mathrm{Al}}^{\text {Rejected }}\right],
\end{aligned}
$$



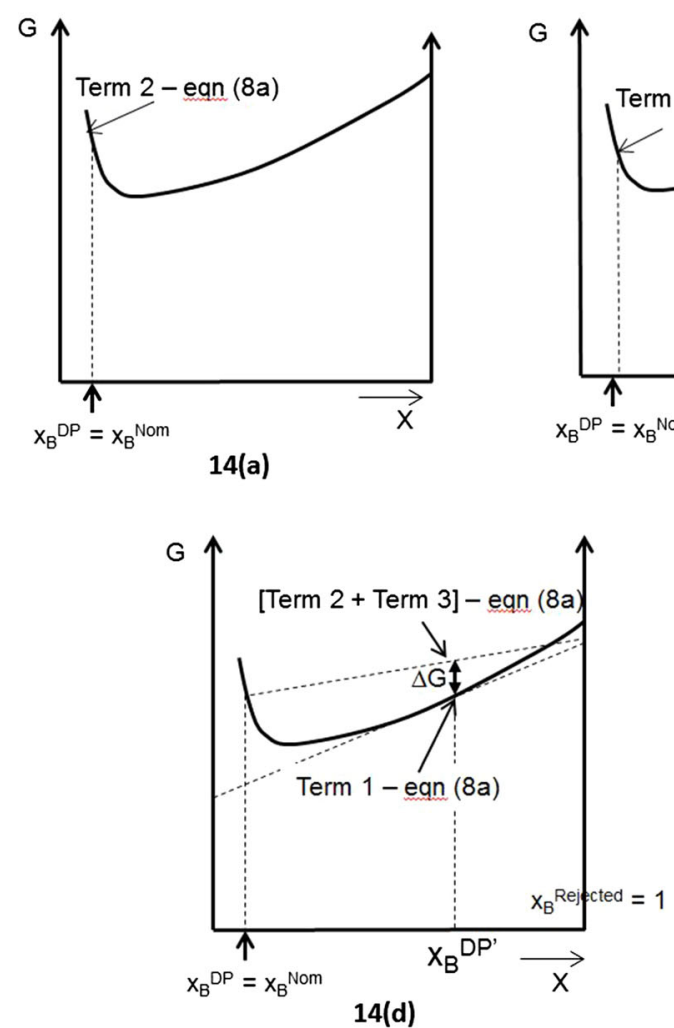
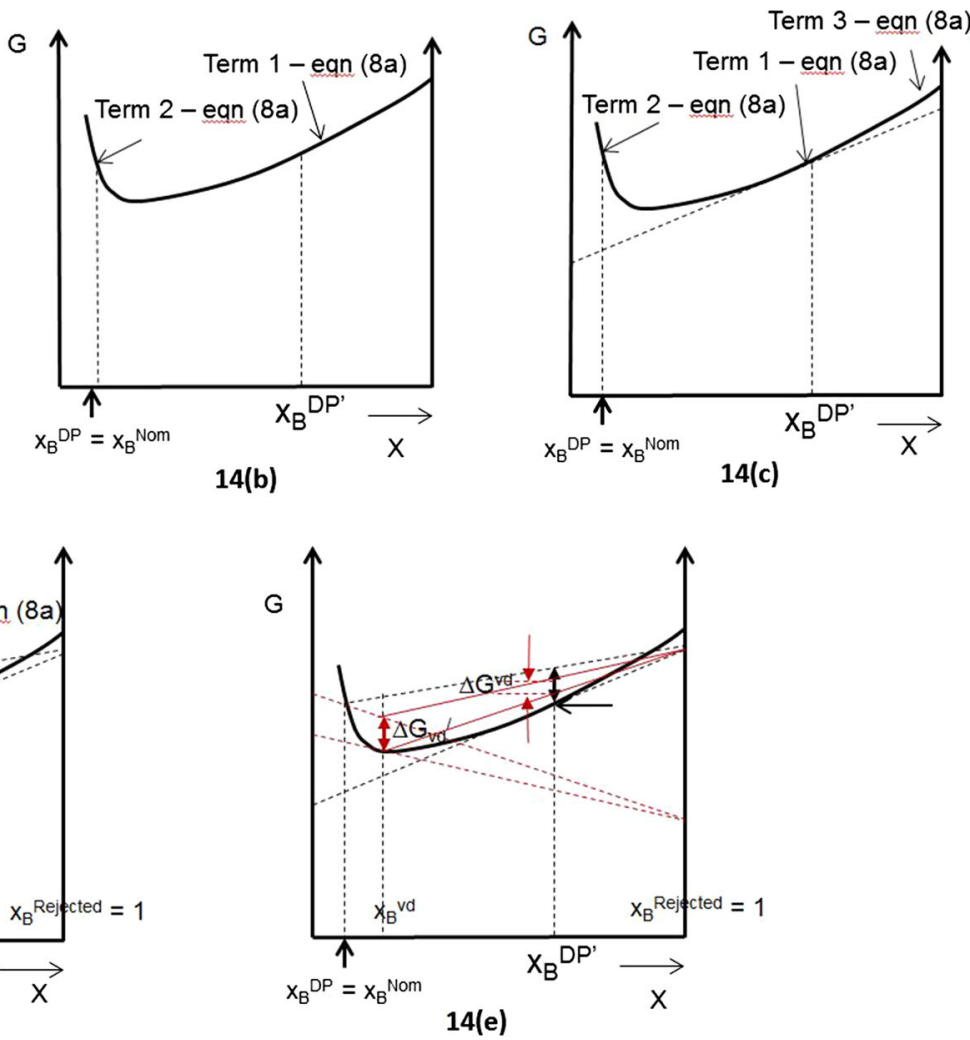

Fig. 15-Molar Gibbs free energy diagram ( $\mathrm{G} v s \mathrm{x})$ showing the various terms in the calculation of the free energy change for discontinuous precipitation in a binary system: $(a)$ through $(d)$ Calculation of driving force, c.f. Eq. [8a], (e) Loss of driving force from volume diffusion, c.f. Eqs. [11c] and [11d].

The loss in driving force arises from diffusion of $\mathrm{Al}$ ahead of the DP cell interface and corresponds to the mole-fraction of $\gamma^{\prime}$ that subsequently nucleates and grows ahead of the DP cell. Using the superscript "vd" to refer to volume diffusion, the loss in driving force can be calculated as follows:

$$
\begin{aligned}
& x_{i}^{\mathrm{vd}}=\frac{n_{i}^{\mathrm{vd}}}{\sum_{i} n_{i}^{\mathrm{vd}}}=\frac{t^{\mathrm{Nom}} \cdot x_{i}^{\mathrm{Nom}}}{\sum_{i} t^{\mathrm{Nom}} x_{i}^{\mathrm{Nom}}+n_{A l}^{\text {Rejected(vd) }}} \quad i \neq A 1 \\
& x_{i}^{\mathrm{vd}}=\frac{n_{i}^{\mathrm{vd}}}{\sum_{i} n_{i}^{\mathrm{vd}}}=\frac{t^{\mathrm{Nom}} \cdot x_{\mathrm{Al}}^{\mathrm{Nom}}+n_{\mathrm{Al}}^{\text {Rejected(vd) }}}{\sum_{i} t^{\mathrm{Nom}} x_{i}^{\mathrm{Nom}}+n_{\mathrm{Al}}^{\text {Rejected(vd) }}} \quad i=\mathrm{A} 1 .
\end{aligned}
$$

The free energy change is then calculated per mole of "vd":

$\Delta G^{\prime}=G(\mathrm{vd} \prime)-\left[f^{\mathrm{vd}} \sum_{i} \mu_{i}^{\mathrm{vd}} x_{i}^{\mathrm{vd}}+\mu_{\mathrm{Al}}^{\mathrm{Rejected}}\left(x_{\mathrm{Al}}^{\mathrm{vd}}\right) f_{\mathrm{Al}}^{\mathrm{Rejectd}(\mathrm{vd})}\right]$,

where $f^{\mathrm{vd}}+f_{\mathrm{Al}}^{\text {Rejected(vd) }}=1$. If $\Delta G$ is to be calculated per mole of composition, $x_{i}^{\mathrm{DP}^{\prime}}$,

$$
\Delta G^{\prime \prime}=\left[\frac{1-x_{\mathrm{Al}}^{\mathrm{DP} \prime}}{1-x_{\mathrm{Al}}^{\mathrm{vd}}}\right] \Delta G^{\prime} .
$$

Therefore, the net driving force for pulling the grain boundary is given by

$$
\Delta G^{\mathrm{Net}}=\Delta G-\Delta G^{\prime \prime}
$$

where $\Delta G$ is given by Eq. [10c].

Referring to Figure 2, the solvus temperature is $T=1362{ }^{\circ} \mathrm{C}$, while in Figure $12, \gamma^{\prime} \approx 4$ pct at the commencement of isothermal hold. There are two important aspects that pertain to $\gamma^{\prime}$ measured using neutron diffraction.

- First, the measured $\gamma^{\prime}$ percentage only corresponds to $\gamma^{\prime}$ that has nucleated epitaxially and possessing the orientation of the substrate and therefore precludes the DP zone. This therefore unequivocally refers to $\gamma^{\prime}$ nucleated from diffusion of $\mathrm{Al}$ ahead of the DP zone.

- Second, the gage volume of the neutron beam is a sphere of diameter $\sim 1 \mathrm{~mm}$ into the surface, and therefore, the measured $\gamma^{\prime}$ fraction corresponds to the amount present in this volume.

It follows therefore that at $T=1350{ }^{\circ} \mathrm{C}$, i.e., before the isothermal hold $\gamma^{\prime} \approx 4$ pct refers to the remnant 
un-dissolved $\gamma^{\prime}$ precipitate within the $\gamma^{\prime}$ matrix. Also since $\gamma^{\prime} \approx 7.5$ pct at the end of isothermal hold, it can be inferred that $\Delta \gamma^{\prime} \approx 3.5$ pct corresponds to $\gamma^{\prime}$ nucleated from diffusion of Al ahead of the DP cell. From Figure 7(a), it is clear that $\gamma^{\prime}$ nucleated ahead of the DP zone is confined to within $\sim[75$ to 100$] \mu \mathrm{m}$ ahead of the interface. However, it is not possible to ascertain the amount present at $1623 \mathrm{~K}\left(1350{ }^{\circ} \mathrm{C}\right)$ from this micrograph, since subsequent growth would have occurred during cooling at the end of isothermal hold. For this purpose, we use the $\gamma^{\prime}$ fraction measured using in situ neutron diffraction as a guide for determining the fraction existing ahead of the interface at $1623 \mathrm{~K}\left(1350{ }^{\circ} \mathrm{C}\right)$.

This is done as follows:

Step I-Assuming constant molar volume, the total number of moles of elements in a layer is proportional to the layer thickness; $n_{i}=x_{i} \cdot t$, where $x_{i}$ is molefraction. Given the average gage volume of the neutron beam, we take $t_{\text {Alloy }} \sim 1000 \mu \mathrm{m}$ and having nominal composition $\left(x_{i}^{\mathrm{Nom}}\right)$.

Step II-For different values of $n_{\mathrm{Al}}^{\text {Rejected }}$ and with $t^{\text {Nom }}=t_{\text {Alloy }} \sim 1000$, calculate the composition from Eqs. [11a] and [1 1 b] and subsequently determine the phase fraction at $1623 \mathrm{~K}\left(1350{ }^{\circ} \mathrm{C}\right)$ for these compositions.

Step III-The $\gamma^{\prime}$ percentage calculated in Step II should be 7.5 pct at $1623 \mathrm{~K}\left(1350{ }^{\circ} \mathrm{C}\right)$, since this is the experimentally measured $\gamma^{\prime}$ fraction [Figure 12], within the gage volume. This therefore gives $n_{\mathrm{Al}}^{\text {Rejected }} \sim 250$, which are the number of moles of Al within $1 \mathrm{~mm}$ from the surface.

Step IV-However, referring to Figure 7(a), the moles of Al diffusing ahead of the interface ( $n_{\mathrm{Al}}^{\text {Rejected }}$ ) are actually contained only within $\sim[75$ to 100$] \mu \mathrm{m}$ ahead of the DP zone interface. Therefore, the composition of the region affected by volume diffusion calculated using Eqs. [11a] and [11b] corresponds to, $t^{\text {Nom }}=t_{\text {Alloy }} \sim[75$ to 100$] \mu \mathrm{m}$ and $n_{\mathrm{Al}}^{\text {Rejected }} \sim 250$.

Therefore from Eqs. [11a] and [11b], the composition of the primary solute species within this region in atom percent is given by

$\mathrm{Al}=16.4, \quad \mathrm{Co}=3.29, \quad \mathrm{Cr}=1.81, \quad \mathrm{Ta}=2.83$, $\mathrm{W}=1.82, \operatorname{Re}=2.22$, and $f^{\mathrm{vd}}=0.968$ and $f_{\mathrm{Al}}^{\text {Rejected(vd) }}$ $=0.032$. This gives, $\gamma^{\prime}=35$ pct and $\gamma=65$ pct. Therefore,

- There is a near sevenfold increase in $\gamma^{\prime}$ fraction at $1623 \mathrm{~K}\left(1350{ }^{\circ} \mathrm{C}\right)$ compared to the start of isothermal hold within [75 to 100] $\mu \mathrm{m}$ ahead of the interface.

- Following cooling to room temperature, there is a further twofold increase in $\gamma^{\prime}$ fraction $\left[\gamma^{\prime} \sim[70\right.$ to 80] pct from an area fraction measure].

Also, from Eq. [11c], $\Delta G^{\prime}=-0.196 \mathrm{~kJ} \mathrm{~mol}^{-1}$. This is the free energy loss corresponding to volume diffusion per mole of material with composition calculated above. In the case of free energy loss per mole of $\mathrm{DP}^{\prime}$, Eq. [11d] has to be used.

On the other hand, unlike in the earlier stages of DP, the calculation of the driving force during the latter stages of DP is not straightforward, since we need to know Al contained within the DP cell, which is not easy to ascertain. Therefore, we will only restrict the calculations to the loss of driving force. It is worth pointing out, however, that with decreasing Al retained in the DP cell $\left(x_{\mathrm{Al}}^{\mathrm{DP}^{\prime}}\right)$ and increasing $\mathrm{Al}$ diffusing ahead of the DP cell interface $\left(\mathrm{x}_{\mathrm{Al}}^{\mathrm{vd}}\right)$, this loss in driving force when calculated per mole of $\mathrm{DP}^{\prime}$ increases [Eq. 11d].

The nucleation and growth of $\gamma^{\prime}$ precipitates from super-saturation of $\mathrm{Al}$ must be accompanied by rejection of $\mathrm{Cr}, \mathrm{W}$, and $\mathrm{Re}$ to the adjacent $\gamma$ phase, since specifically $\mathrm{Cr}$ and $\operatorname{Re}$ have negligible solubility in $\gamma^{\prime}$. When grain boundary diffusion is dominant, growth of the DP cell $\left[\gamma+\mathrm{Al} \rightarrow \gamma^{\prime}+\mathrm{TCP}\right]$ is maintained, where excess $\mathrm{Cr}, \mathrm{W}$, and $\operatorname{Re}$ from $\gamma$ is transported by shortcircuit diffusion along the grain boundary to the growing tips of the TCP's. However, when volume diffusion is dominant, Al diffuses ahead of the grain boundary. Owing to sluggish transformation kinetics of these precipitates in the absence of heterogeneous sites, such as grain boundaries, ${ }^{[30,31]}$ the nucleation of the TCP phases within $\gamma$-channels is suppressed. Therefore, $\mathrm{Cr}, \mathrm{W}$, and $\mathrm{Re}$ rejected accompanying the nucleation and growth of $\gamma^{\prime}$ have to be accommodated within the $\gamma$-channels, which will then become super-saturated. This is clearly observed in Figure 10, where there is an increased segregation of $\mathrm{Cr}$ and $\mathrm{W}$ (Section III-B-1) in the $\gamma$-channels in the vicinity of the DP cell interface compared to the bulk.

\section{Micro-structural Evidence for Loss of Driving Force}

From the preceding sections, it is clear that volume diffusion results in a diminishing of the driving force that drives DP and will retard the advancement of the DP cell. A simple experiment can demonstrate this principle very elegantly. The basis of the experiment is dependent on two requirements:

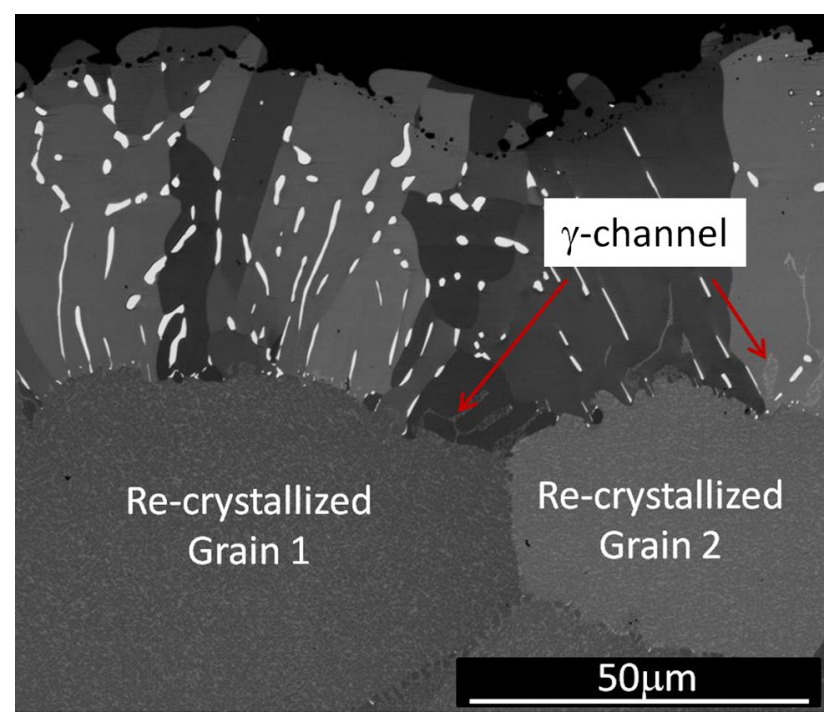

Fig. 16-Back-scattered electron image showing nucleation of two re-crystallized grains ahead of the DP zone after solutioning at $1623 \mathrm{~K}\left(1360{ }^{\circ} \mathrm{C}\right)$ for $1 \mathrm{~h}$ 
- Prior to heat treatment, imparting of surface strain to a test bar (pre-straining), so that there exists a second driving force for grain growth in addition to solute super-saturation.

- Heat treating the test bar at/close to the solvus temperature, but at the same time decrease the chemical driving force for discontinuous precipitation. Since the latter arises from vaporization, this can be achieved by solutioning in an environment saturated with $\mathrm{Ni}$ vapor, such as the use of "sacrificial" Ni-foils interspersed within the furnace to minimize $\mathrm{Ni}$ vaporization losses from the test bar. ${ }^{[32]}$

Figure 16 is a BEI that shows the DP cells growing from the surface into the substrate, where the microstructure is similar to that observed in Figures 3(a) and 4(b) although there is also some evidence of $\gamma$ lamellae within the cells at the grain boundary. However, there exists one fundamental difference - there is the nucleation and growth of two re-crystallized grains ahead of the DP cell interface (grain boundary) and which subsequently grow into the substrate. The $\gamma^{\prime}$ morphology within these grains clearly indicates that these grains have nucleated in the single $\gamma$ phase-field. Since there exists a grain boundary at the DP cell interface that precedes the nucleation of these grains, any remnant plastic strain that is dissipated would not require "new" nucleation. In fact, the growth of a strain-free grain would be sustained by the advancement of the DP cell boundary. However, if this were the case, advancement of this boundary would be necessarily constrained by growth of the TCP needles, whose tips outline the grain boundary. Growth is then driven by solute super-saturation requiring partitioning of $\mathrm{Cr}, \mathrm{W}$, and $\mathrm{Re}$ along the boundary to the precipitate tips. But if super-saturation is absent, the boundary will be "pinned" by the TCP needles. Therefore, dissipation of strain would then require nucleation of a "new" grain at the existing DP boundary and subsequent growth of this new grain will not be constrained by solute super-saturation, which is consistent with the observations in Figure 16.

\section{CONCLUSIONS}

The schematic diagram in Figure 13 summarizes the various stages in discontinuous precipitation and subsequent calculations. The key conclusions are

(1) Discontinuous precipitation (DP) was shown to be operative even at temperatures approaching the solvus, where volume diffusion prevails over grain boundary diffusion.

(2) There is minimal loss of driving force below typically $1573 \mathrm{~K}\left(1300{ }^{\circ} \mathrm{C}\right)$, when grain boundary diffusion dominates. With increasing temperature, volume diffusion becomes dominant and is accompanied by a loss in the driving force for advancement of the grain boundary. This is primarily concomitant with diffusion of Al ahead of the boundary.

(3) In the growth of DP cell, transformation of $\gamma \rightarrow \gamma^{\prime}$ is accompanied by partitioning of $\mathrm{W}, \mathrm{Re}$, and $\mathrm{Cr}$ to the growing tips of the TCP precipitates. However, when volume diffusion is dominant, transformation of $\gamma \rightarrow \gamma^{\prime}$ ahead of the interface is accompanied by super-saturation of $\mathrm{Cr}, \mathrm{W}$, and $\mathrm{Re}$ within the $\gamma$-channels ahead of the DP cell. This arises since TCP-phase nucleation is suppressed owing to the absence of heterogeneous sites and excess $\mathrm{Cr}, \mathrm{W}$, and $\mathrm{Re}$ are therefore accommodated within $\gamma$-channels.

(4) From thermodynamics, the driving force was calculated for the initial stages of DP and was $\left[10^{-5}\right.$ to $\left.10^{-4}\right] \mathrm{N} /\left[\mu \mathrm{m}^{2}\right.$ of the grain boundary]. Nearly all of this force was available to pull the grain boundary. A method for estimating the loss of driving force when volume diffusion occurs was also presented.

\section{OPEN ACCESS}

This article is distributed under the terms of the Creative Commons Attribution 4.0 International License (http://creativecommons.org/licenses/by/4.0/), which permits unrestricted use, distribution, and reproduction in any medium, provided you give appropriate credit to the original author(s) and the source, provide a link to the Creative Commons license, and indicate if changes were made.

\section{REFERENCES}

1. R.C. Reed: The Superalloys: Fundamentals and Applications, Cambridge University Press, Cambridge, UK, 2006.

2. I. Manna, S.K. Pabi, and W. Gust: Int. Mater. Rev., 2001, vol. 46, pp. 53-91.

3. W.S. Walston, J.C. Schaeffer, and W.H. Murphy: in Superalloys, R.D. Kissinger et al., eds., The Minerals, Met. Mater. Soc., TMS Warrendale, 1996, pp. 9-18.

4. A. Suzuki, C.M.F. Rae, M. Yoshida, Y. Matsubara, and H. Murakami: in Superalloys 2008, R.C. Reed et al., eds., TMS, Warrendale, 2008, pp. 777-86.

5. C.M.F. Rae, M.S. Hook, and R.C. Reed: Mater. Sci. Eng. A, 2005, vol. 396, pp. 231-39.

6. J.D. Nystrom, T.M. Pollock, W.H. Murphy, and A. Garg: Met. Mater. Trans. A, 1997, vol. 28A, pp. 2443-52.

7. A. Heckl, S. Neumeier, S. Cenanovic, M. Goken, and R.F. Singer: Acta Mater., 2011, vol. 59, pp. 6563-73.

8. A. Heckl, S. Cenanovic, M. Goken, and R.F. Singer: Mater. Trans. A., 2012, vol. 43A, pp. 10-19.

9. G. Xie, J. Zhang, and L.H. Lou: Scr. Met., 2008, vol. 59, pp. 85861.

10. J.M. Oblak and W.A. Owczarski: Trans. Met. Soc. AIME, 1968, vol. 242, pp. 1563-68.

11. J. Meng, T. Jin, X.-F. Sun, and Z. Hu: Int. J. Min Met. Mater., 2011, vol. 18, pp. 197-202.

12. A. Porter and B. Ralph: J. Mater. Sci., 1981, vol. 16, pp. 707-13.

13. R. Burgel, P.D. Portella, and J. Preuhs: in Superalloys 2000, T.M. Pollock et al., eds., TMS (Min. Met. Mater. Soc.), Pittsburgh, PA, pp. 229-38.

14. M. Dahlen and L. Winberg: Acta Metall., 1980, vol. 28, pp. 41-50.

15. M. Hillert:, in The Mechanisms of Phase Transformations in Crystalline Solids, Proc. of International Symposium., Monograph and Report Series No. 33, R.B. Nicholson, J.W. Christian, G.W. Greenwood, J. Nutting, and R.D. Smallman, eds., Inst. Of Metals, Manchester, 1968, pp. 231-47.

16. M. Hillert: Metall. Trans., 1972, vol. 3, pp. 2729-41.

17. M. Kajihara and W. Gust: Scripta Mater., 1994, vol. 38, pp. 1621-27.

18. H.B. Dong and J.D. Hunt: J. Thermal. Anal. Calorim., 2001, vol. 64, pp. 167-176. 
19. C. Schulze and M. Feller-Kniepmeier: Mater. Sci. Eng. A, 2000, vol. A281, pp. 204-212.

20. N. D'Souza, R. Beanland, C.L. Hayward, and H.B. Dong: Acta Mater., 2011, vol. 59, pp. 1003-13.

21. H.J. Stone, M.J. Peet, H.K.D.H. Bhadeshia, P.J. Withers, S.S. Babu, and E.D. Specht: Proc. Roy. Soc., 2008, vol. 464, pp. 1009-1027.

22. C.B. Alcock, V.B. Itken, and M.K. Horrigan: Can. Met. Quart., 1984, vol. 23, pp. 309-313.

23. N. D’Souza, D. Welton, G.D. West, I.M. Edmonds, and H. Wang: Metall. Trans. A, 2015, vol. 45, pp. 5968-81.

24. D. Liu, W.A. Miller, and K.T. Aust: Metall. Trans. A., 1988, vol. 19A, pp. 1667-75.

25. H.-C. Yu, A. Van der Ven, and K. Thornton: Metall. Mater. Trans. A, 2012, vol. 43A, pp. 3481-3500.
26. F.S. Petit: Trans. Met. Soc. AIME, 1967, vol. 239, pp. 12961305.

27. L. Bencze, D.D. Raj, D. Kath, W.A. Oates, L. Singheiser, and K. Hilpert: Metall. Mat. Trans. B, 2004, vol. 35B, pp. 867-76.

28. JMatPro: Ni module (Version 2.0), Sente Software, Guilford, UK (2002).

29. M.D. Sangid, H. Sehitoglu, H.J. Maier, and T. Niendorf: Mater. Sci. Eng. A, 2010, vol. 527, pp. 7115-25.

30. R. Darolia, D.F. Lahrman, and R.D. Field: in Superalloys, S. Reichman et al., eds., The Minerals, Met. and Mater. Soc., TMS Warrendale, PA, 1988, pp. 255-64.

31. C.M.F. Rae and R.C. Reed: Acta Mater., 2001, vol. 49, pp. 4113-25.

32. H. Wang, N. D'Souza, S. Zhao, D. Welton, N. Warnken, and R.C. Reed: Scripta Mater., 2014, vols. 78-79, pp. 45-48. 